\title{
Growth and integration's impact under a new dynamic approach
}

\author{
Monica Laura Zlati ${ }^{1} \cdot$ Romeo Victor lonescu$^{2} \cdot$ Valentin Marian Antohi ${ }^{3}$ (D) \\ Veronica Grosu ${ }^{1}$
}

Received: 5 July 2020 / Accepted: 3 August 2021 / Published online: 17 August 2021

(C) The Author(s), under exclusive licence to Springer Nature B.V. 2021

\begin{abstract}
The aim of the research is to define a new model able to quantify the viability of one or more economies' growth and integration within a regional entity. The final goal of such approach is to support the European adhering process in the context of the present pandemic. Our approach is a dynamic one and is focused on the Balkan region as main supplier of candidate countries. The methods used in the analysis are represented by the metaanalysis of the literature in the field, comparison of statistical databases, dedicated software and application of the degree of concentration theory (author Zlati Monica-Laura). Using this theory, a new statistical model is built. Its results will generate significant conclusions regarding the impact and performance of the two economies' integration.
\end{abstract}

Keywords Growth · Integration · Adhering process · Dynamic approach · Regional entity

\section{Introduction}

The European economy has undergone a business cycle foldable on the Markov chains. After the latest economic crisis, EU achieved six consecutive years of economic growth. This period was marked by increased tensions in global trade relations and significant fluctuations of the economic growth in real GDP terms against the background of Brexit.

Valentin Marian Antohi

valentin_antohi@yahoo.com

Monica Laura Zlati

sorici.monica@usm.ro

Romeo Victor Ionescu

ionescu_v_romeo@yahoo.com

Veronica Grosu

doruveronica@yahoo.it

1 Department of Accounting, Audit and Finance, Stefan Cel Mare University, Suceava, Romania

2 Department of Administrative Sciences and Regional Studies, Dunarea de Jos University, Galati, Romania

3 Department of Business Administration, Dunarea de Jos University, Galati, Romania 
Moreover, the economic conflict between EU and USA and China's greater global economic impact represent real challenges for the European economy.

EU27 has taken the political decision to continue the enlargement process post-Brexit. As a result, the European officials' statements anticipate a new enlargement of the EU at the horizon of 2025. The European Neighbourhood Policy Commissioner Johannes Hahn nominated Serbia and Montenegro as the future Member States. This is why, the European Commission adopted a specific road map for both economies (Stone, 2018).

As the EU continues to remain an open organization, our scientific approach is current and important in terms of economic development, European integration and the dynamization of the integration process. The regionalization process across the EU requires a dynamic approach both in terms of financing development and the cohesion process, as well as in terms of creating regional sustainability nuclei capable of generating progress.

According to official data from the European Commission (European Commission, 2020), Germany will manage to eliminate the effects of the Covid-19 pandemic by 2022 , achieving a GDP growth of $6.1 \%$ over this period.

Montenegro is facing major economic difficulties caused by the crisis in tourism and retail, which are key sectors for the economy. However, the growth rates are positive and relatively high during 2021-2022.

Serbia suffered an economic compression of only $1.8 \%$ of GDP during the pandemic. As a result, the economic recovery is much easier, as it is expected to finish at the end of 2021.

In this context, the present study aims at a logical approach based on official statistics, able to anticipate the process of further EU enlargement.

Using the statistical information available for the economies of these three analysed countries, of which Germany is a pole of economic growth and the economies of Serbia and Montenegro are emerging economies with accession potential, we aim to define a new model able to quantify the viability of one or more economies' development and integration within a regional entity.

A first contribution to this study is to demonstrate the viability of the EU27 enlargement process in the Balkans. In this regard, we used the latest Eurostat information and built, with their support, a dedicated statistical database.

The second contribution consists in achieving an absolutely new model of economic viability and regional integration.

The third contribution aims at the implementation and validation in practice of the proposed new model.

The study proposed by us, based on the model created for this purpose, becomes a useful tool for analysis on the prospects of the accession and integration process within the EU.

The analysis is focused on the following objectives and research questions:

O1: identification of the impact of Serbia and Montenegro's adhering to the EU27;

O2: quantification of the concentration degree of these two candidate economies towards the core of performance (German economy);

O3: evaluating, using a new concentration theory based on scoring performance, the economic viability and the advantages of the integration for the same two economies.

The remainder of this paper is organized as follows. Section 2 summarizes the dedicated literature review. Section 3 is focused on research methodology. Section 4 takes into account the research's results. Section 5 points out discussions regarding the research's 
results and the possibility to integrate into EU27. Section 6 covers conclusions and puts into discussion the limits of the study, its implications and future developments.

\section{Literature review}

The economic growth models were phased presented by the dedicated literature, according to the conceptual and economic development of global realities.

During the interwar period, some classical models of economic growth (Domar, 1946; Harrod, 1939; Keynes, 1936) had an important impact on the economic theories' polarization.

Subsequently, the concerned issues were (Kaldor, 1963) gross fixed capital formation, output diversification, national economies' convergence (Sala-i-Martin, 1996) and the disparities between macroeconomies (Barro, 2004). Nowadays, special emphasis is on regional economic growth models under the impact of different access to technology and the diversification of regional consumer preferences (Coccia, 2018).

The segment allocated to economic integration studies has diversified since the beginning of this century and covered models and economic integration studies regarding the impact of the technical progress on economic theory (the connection between economicsocial/sociological), provided that public policies have an indirect effect on economic and social integration (Parsons et al., 2005), while the direct effect is manifest in the sector of structural change and is generated by separation of ownership and control. Other integration models were focused on the analysis of cyclical business synchronization across the Euro area and Central and Eastern European neighbouring areas (Jimenez-Rodriguez et.al, 2013). The economic integration was analysed by (Benz et.al, 2014), under the assumption of free trade applied on Rybczynski matrix, in order to characterize the productive structure of the EU Member States and to identify the connections between the main aggregate indicators which generate added value and ergonomic growth of consumption indicators. Lumengo (2017) defined a theory regarding the connection between stock volatility transmissions and the capital gains on the foreign market, in order to quantify the impact of the unequally distributed benefits within the BRICS. Other theories regarding the economic integration were focused on the analysis of the relationship between consumer availability and the accumulated amount of population deposits according to the fiscal policy approaches, which generate regional development asymmetry (Gu et. al., 2015). The connection between economic growth and integration was analysed by Colin and Hashimoto in 2016, using an analysis focused on the impact of the monopoly existence and of the elements connected to these two concepts - productivity growth in its dependence of investment and innovation, the zonal distribution in relation to the market size, the transaction costs and the dissipation of corporate management knowledge.

Table 1 realizes a synthesis and a prioritization based on impact of the most frequently used theoretical models of economic growth and integration.

The information from Table 1 supports the building of an impact diagram using the scoring method realized on the scale $\{-1 ; 0 ; 1 ; 2 ; 3\}$. As a result, the theories from the above table are included in impact classes, as: \{very low impact; low impact; medium; high \}.

Such classification supports the approach in Fig. 1, which points out the actual impact of the economic growth and integration theories. 


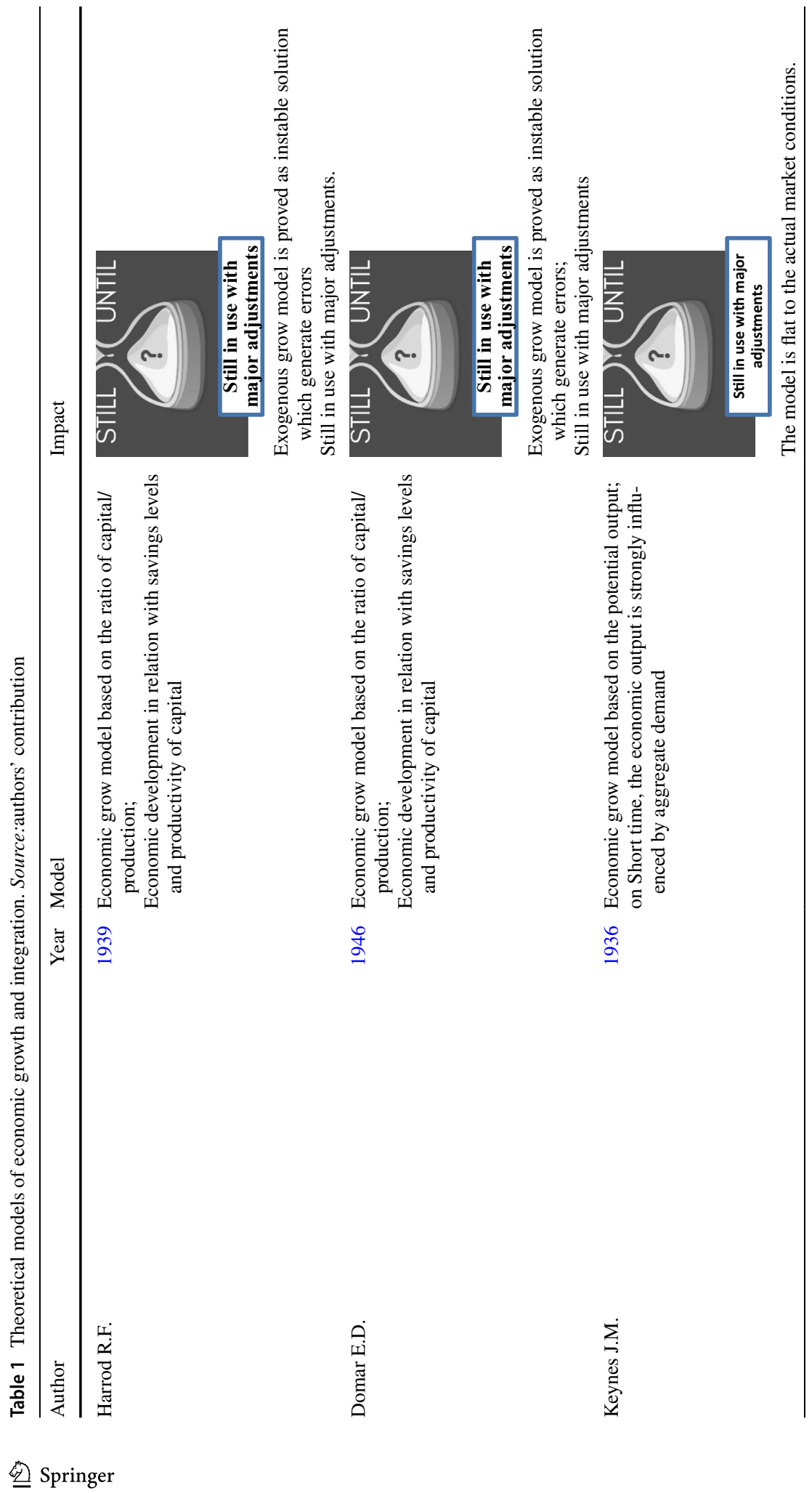




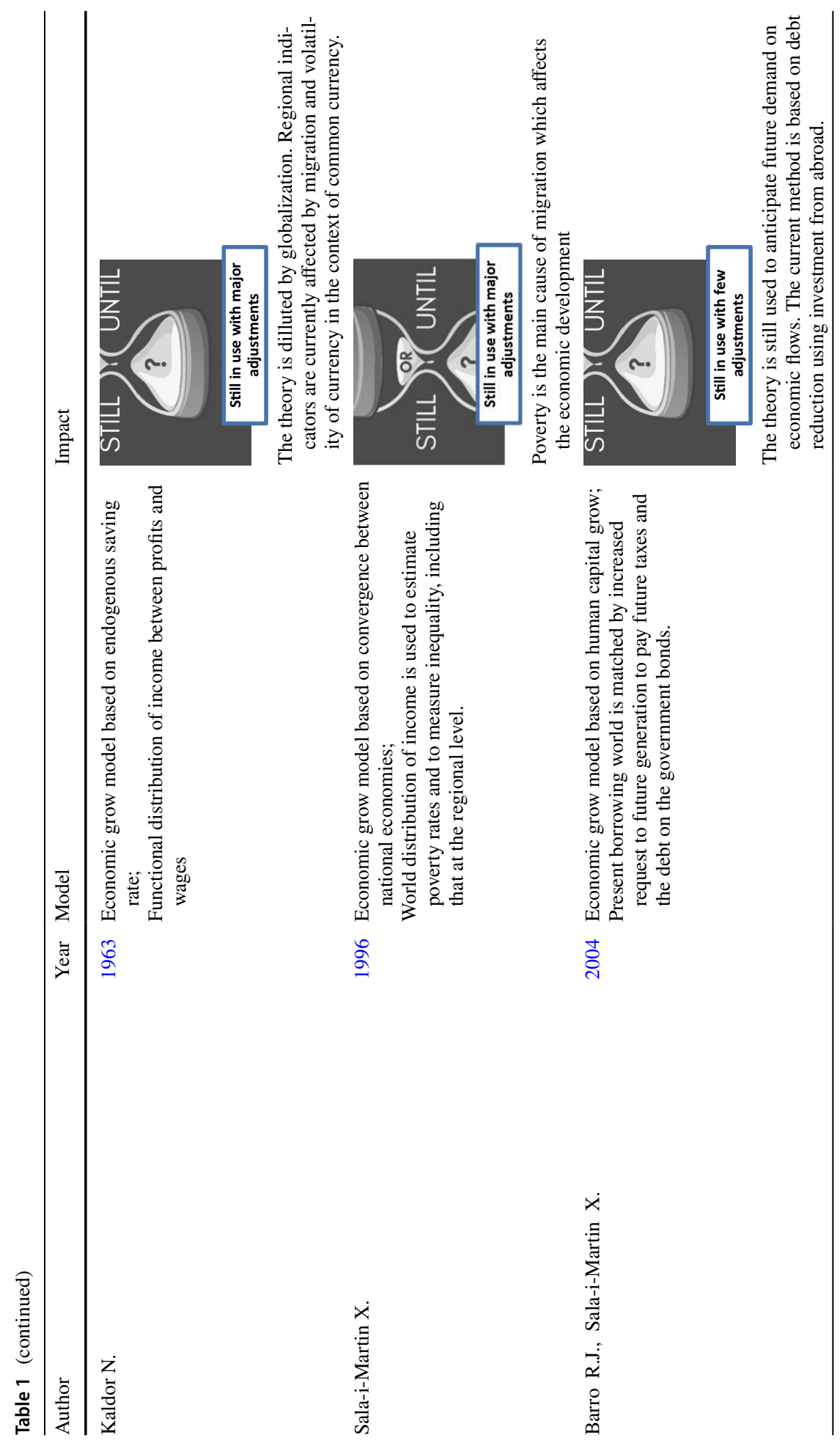




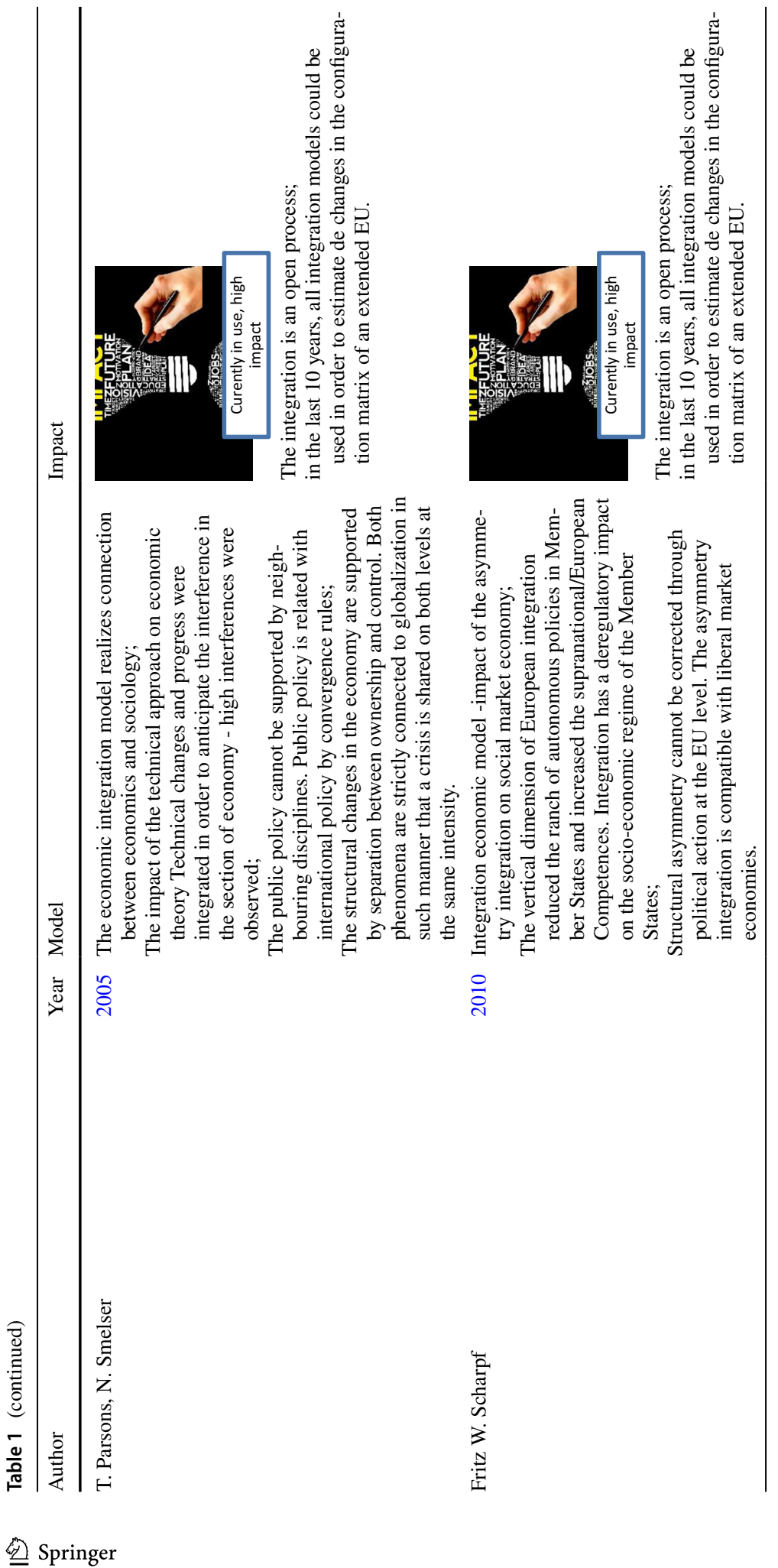




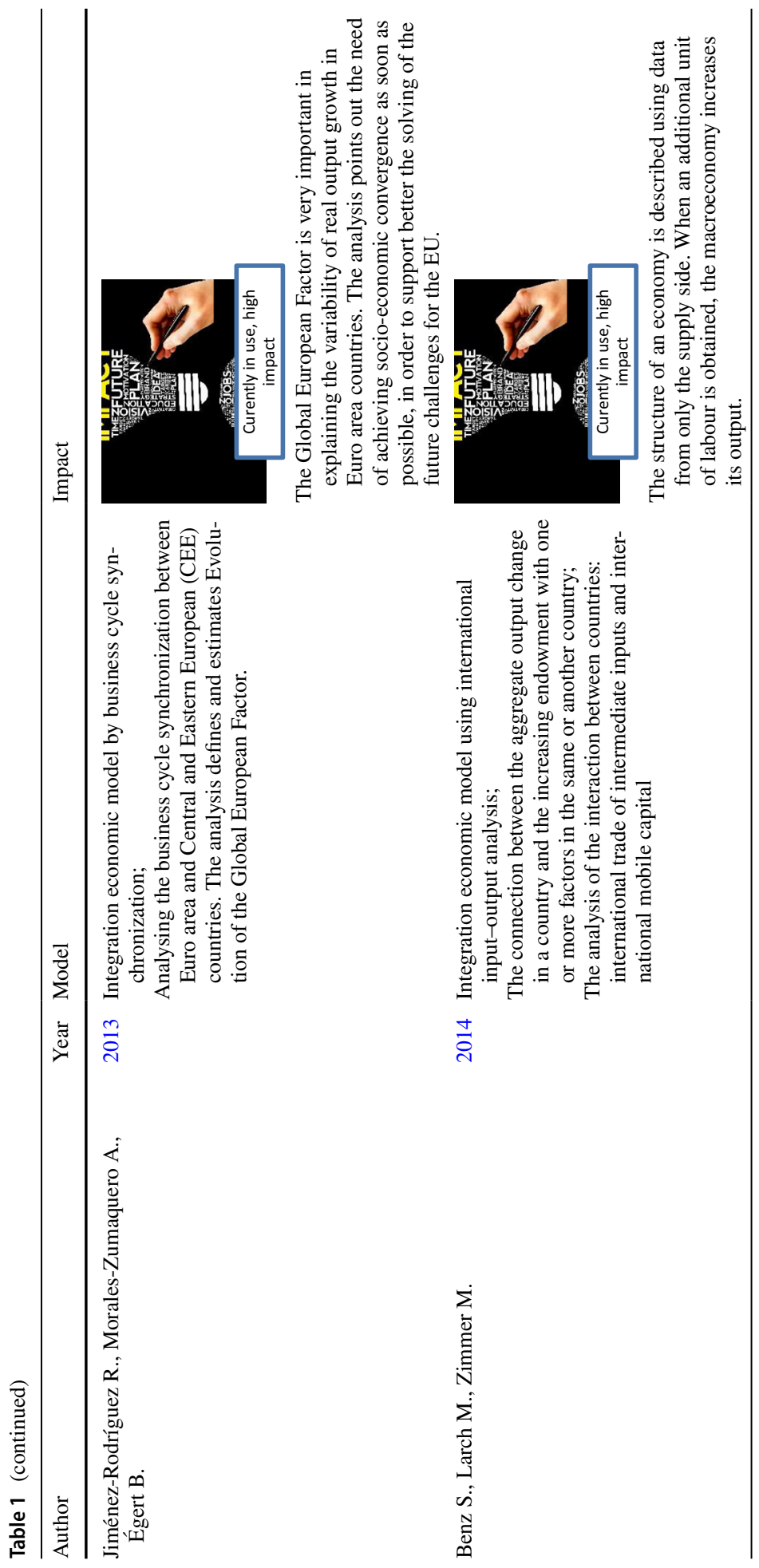




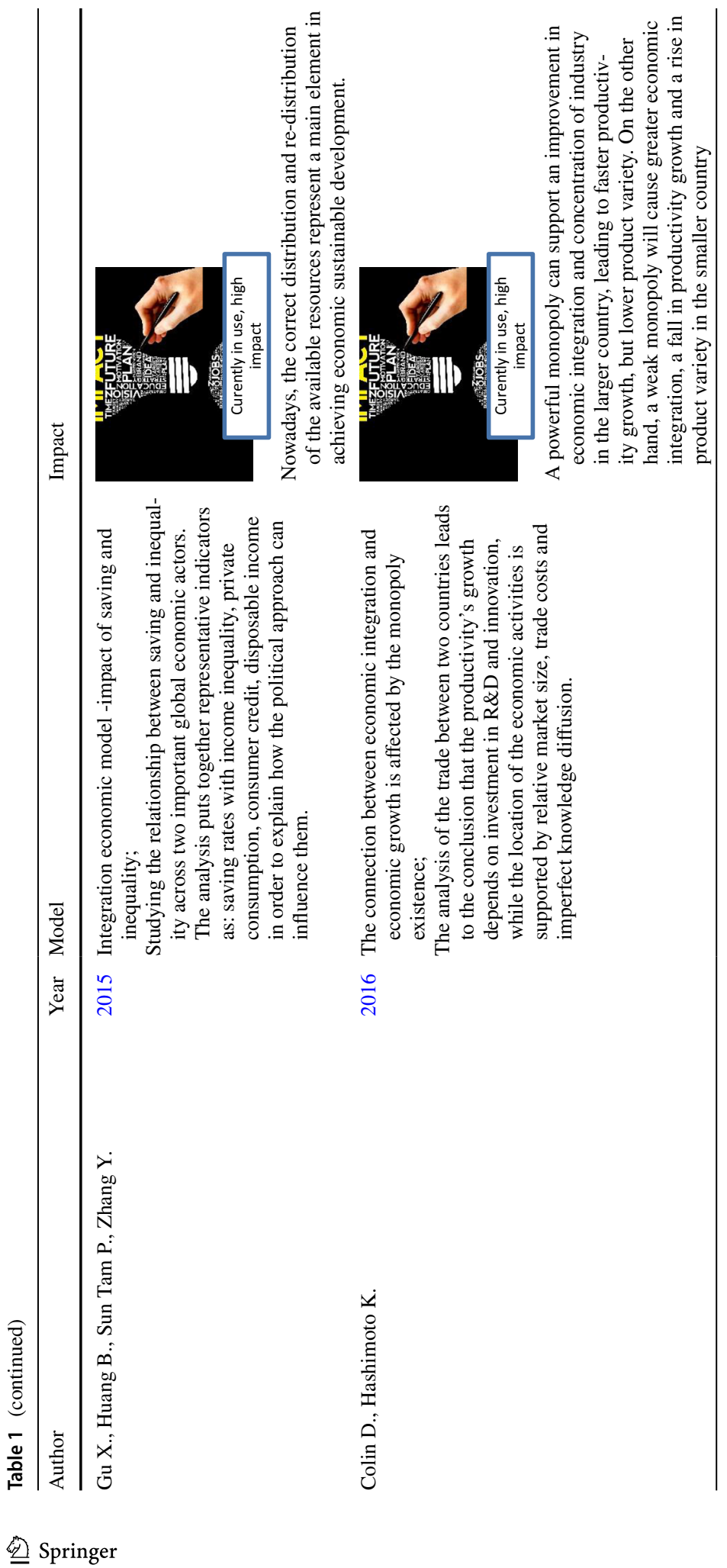




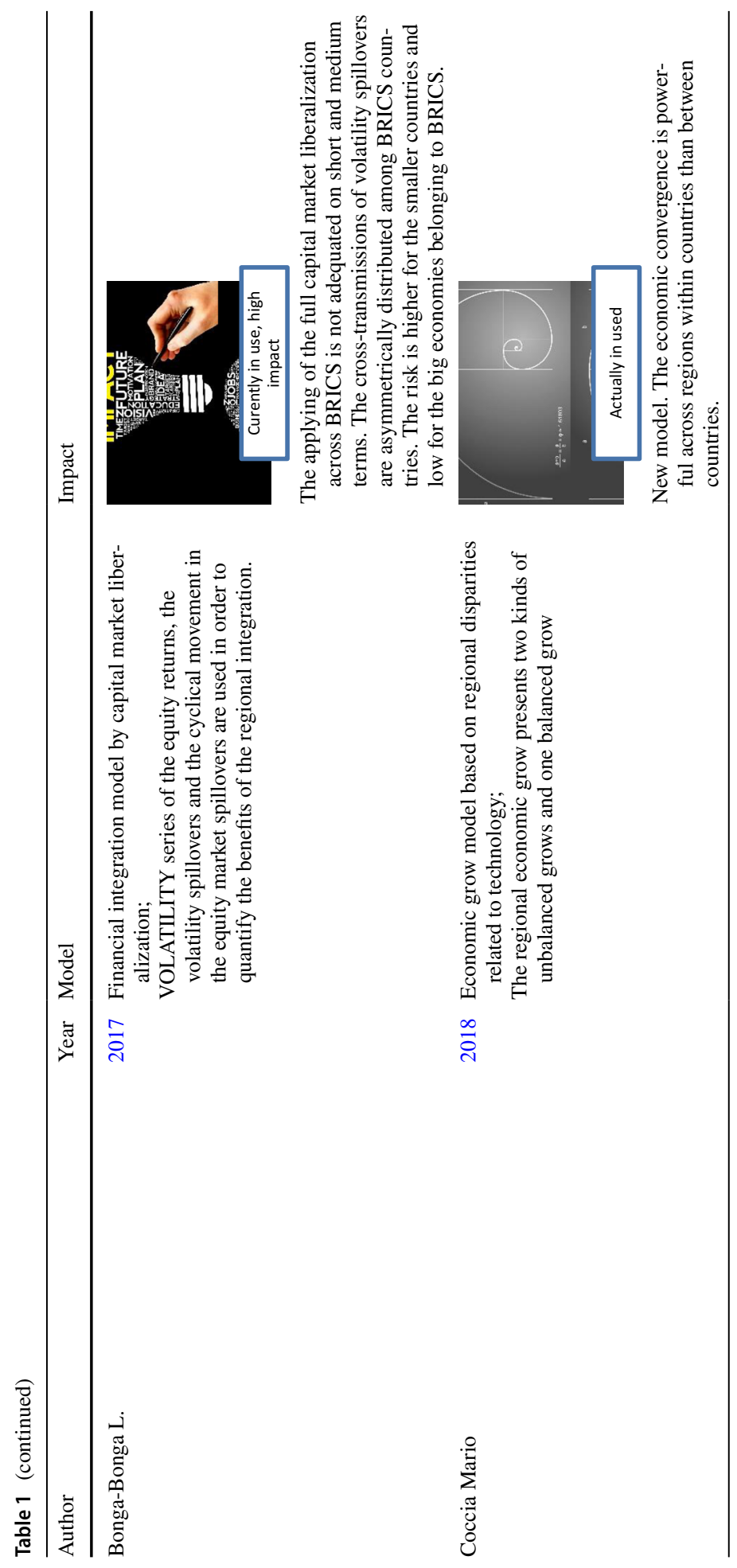




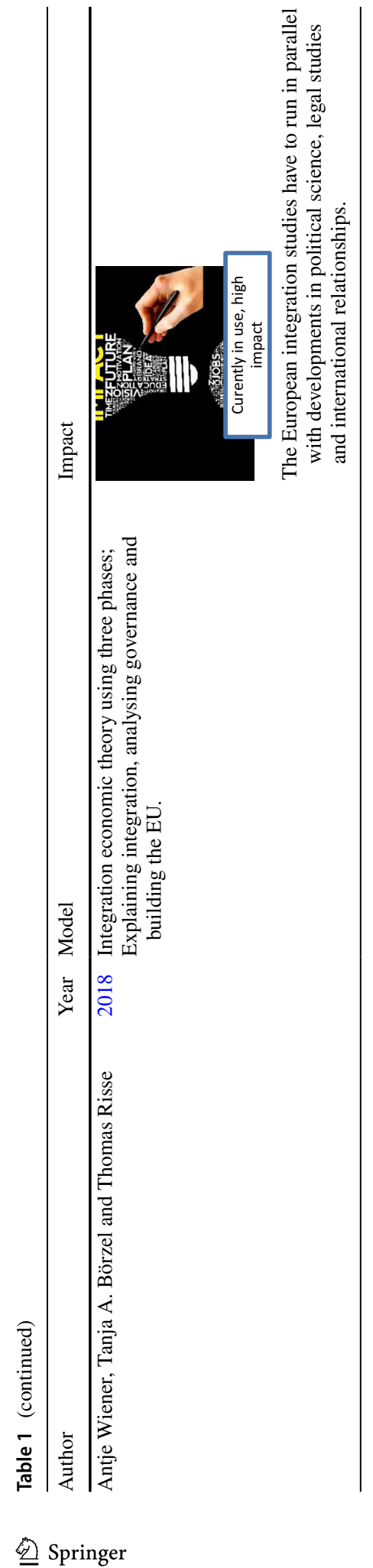




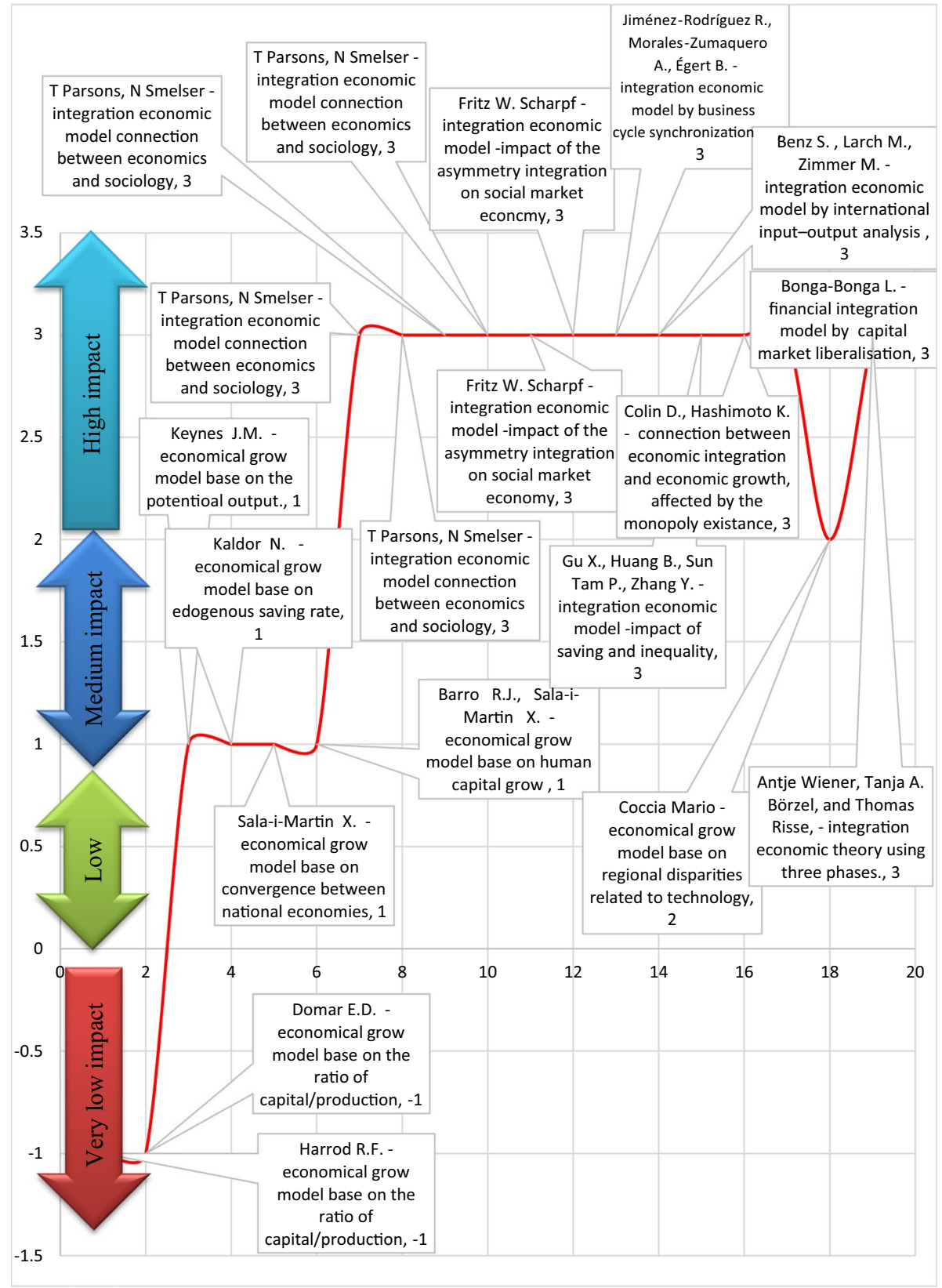

Fig. 1 The actual impact of the economic growth and integration theories. Source: authors' contribution

The difference between the actual application of the models of economic growth and integration was realized using a differential model of radial exposure of the presented theories in Table1 and points out that, in terms of actuality, the integration models 
present higher interest than those of economic growth. This means that the expansion by integration of zonal growth poles is a priority.

Moreover, there are stabilization mechanisms within the economic poles able to ensure a change of the economic growth trend, according to the development pole model (see Fig. 2).

The whole above analysis demonstrates that Serbia and Montenegro's adhering to the EU27 represents high theoretical and practical interest and asks for an analysis of the impact integration of these two economies in relation to the EU economic pole performance (Germany) and an analysis of the integration benefits viability for them.

The present approach proposes a model able to objectively assess the economic development trend and centres, through the elaborated theorem, on the disparities to the economic pole taken as a benchmark. Moreover, the model allows, for the first time, the delimitation of economic fluctuations that an economy can afford to optimally evolve within a regional entity.

\section{Methodology}

In order to achieve the goals of the present research, it is necessary to go through the following algorithm (see Fig. 3).

The model used in the paper was realized by Zlati M.L. under the name of ZML model (Stanciu et al., 2019). It is based on the following theorem:

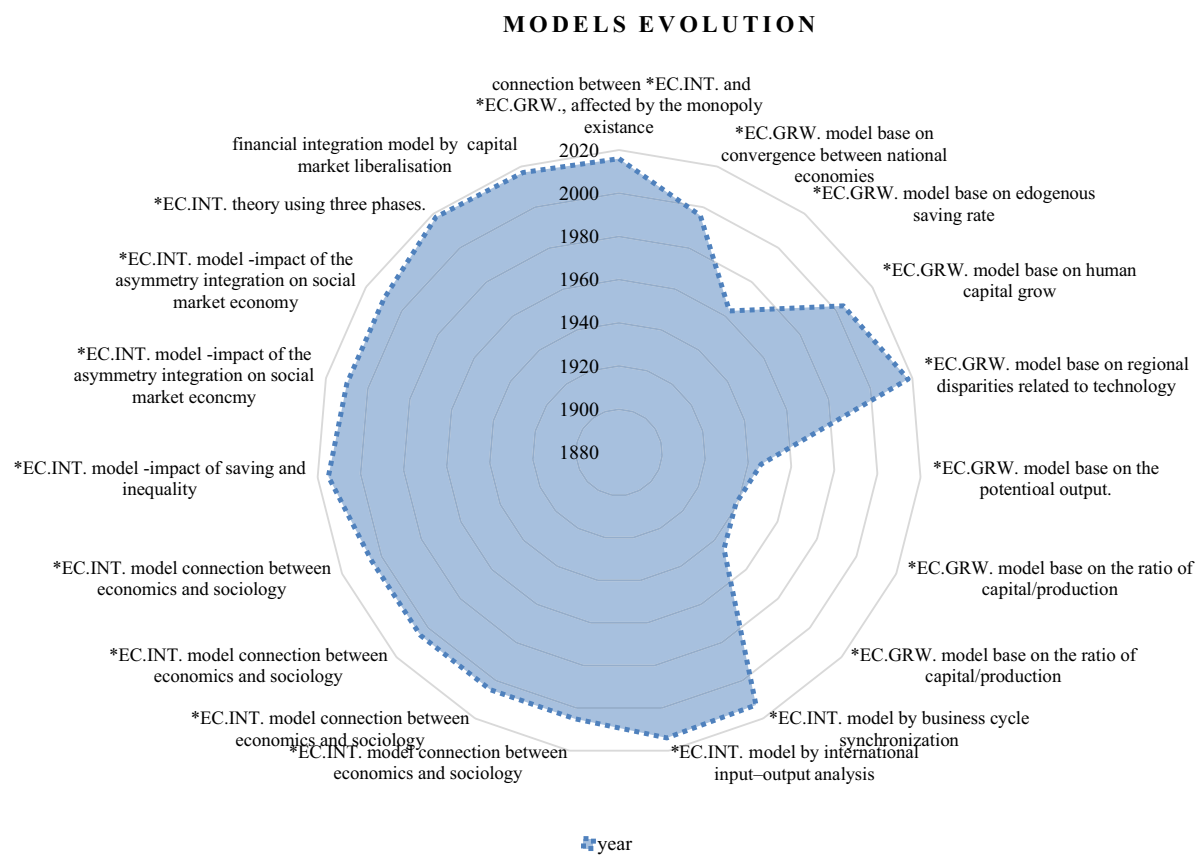

Fig. 2 The evolution of the economic growth (*EC.GRW.) and integration (*EC.INT.) theories' diversification. Source:authors' contribution 


\section{Stage1}

- assessing the current state and the economic development trend for both candidate countries:

- assessing the economic growth rate during the latest 10 years;

- assessing gross fixed capital formation;

- GDP deflator;

- unemployment rate;

- inflation rate;

- general government gross debt.

- assessing the current state and the economic development trend for economic pole of reference (Germany);

- assessing the economic growth rate during the latest 10 years;

- assessing gross fixed capital formation;

- GDP deflator;

- unemployment rate;

- inflation rate;

- general government gross debt.

\section{Stage 2}

- the conceptual definition of the model and its theorem;

- establishing working hypotheses;

- conceptualizing the theorem;

- conceptualizing the model;

- testing the model in relation to existing models.

\section{Stage 3}

- evaluating the model results;

- discussion on the obtained results;

- conclusions.

Fig. 3 The stages of the analysis. Source:authors' contribution

If $\mathrm{Z}^{+} \epsilon \mathrm{N}^{+}$, it represents the set of a series of economic efficiency criteria that respond to a certain level of performance $\alpha_{i}$ :

- $\alpha_{i}$ is the performance criterion which responds to the equation $\alpha_{i}-\alpha$ leader $>0$;

- $\alpha_{\text {leader }}$ represents the performance benchmark of the economic pole of reference (Germania);

- (马) $\alpha_{i}$, with i $\geq 1$ a.i. $\alpha_{i}-\alpha_{\text {leader }}>0$.

As a result, $(\exists) i_{k}$ and $j_{m} a . \backsim(\forall) i_{k} \in j_{m}$ and $(\forall) j_{m} \in Z *, k \in[1, p]$ and $m \in[1, r]$ where:

$p$-number of economic efficiency criteria which respond to a certain level of performance; $m$-the number of the candidate countries took into analysis (Serbia and Montenegro).

To achieve the research objective, we used statistical information published by Eurostat for macroeconomic indicators (economic growth rate; assessing gross fixed capital formation; GDP deflator; unemployment rate; inflation rate; general government gross debt) starting with 2014 (the year of the accession negotiations for Serbia). We used computer 
resources, respectively, the XL program from the Microsoft office package for data consolidation and the dedicated statistical software IBM-SPSS 25.

The model hypotheses are the following: H1. The economic growth is defined by modelling three macroeconomic indicators: GDP, GFC gross fixed capital formation) and PC (public consumption). Under the optimal adhering process, there is an inflexion point which belongs to the GFC segment with an elastic evolution which is optimized by applying the proposed model in the theorems.

H2. The other two indicators of the growth model show sensitivity to domestic macroeconomic conditions and can be optimized by applying the principles of governmental efficiency.

H3 The economic integration is defined using UNE (unemployment rate), HIPC (inflation rate) and GGGD (general governmental gross debt). Under an optimal adhering process, there is an inflexion point on HIPC indicator which is optimized on medium term, after the alignment with the EU's monetary security policies.

H4 The other two indicators (UNE and GGGD) present an optimal evolution during the adhering process, according to the social stabilization policies and the consolidation of the single market.

The above hypotheses lead to the conclusion that $(\exists) i_{k}^{*} \geq(\forall)\left(i_{k}\right)$ and $j_{m}^{*}\left(i_{k}\right) \geq(\forall) j_{k}\left(i_{k}\right)$. so that the function of the concentration degree on the performance cloud peak $\left(Z M L^{*}\right)$ is valid under the following conditions:

$$
\begin{aligned}
& \mathrm{ZML}^{*}=\frac{\sum_{m=1}^{r} j_{m}}{\sqrt{\frac{\sum_{m=1}^{r} j_{m} \cdot\left[1-\left(\frac{i_{k}}{\sum_{k=0}^{p} i_{k}}\right)^{2}\right]}{\left(\sum_{m=1}^{r} j_{m}\right)-1}}>0 \text { and }} \\
& \left\{\begin{array}{l}
\lim _{i \rightarrow \infty}\left(\left|\max \left(i_{k}\right)-\mathrm{ZML}^{*}\right|\right)=\lim _{i \rightarrow \infty}\left(\left|i_{k}^{*}-\mathrm{ZML}^{*}\right|\right) \rightarrow 0 \\
\mathrm{ZML}^{*} \ll \sum_{k=1}^{p} i_{k} \\
\mathrm{ZML}^{*} \rightarrow \sum_{k=1}^{p} i_{k} \Leftrightarrow i \rightarrow 1
\end{array}\right.
\end{aligned}
$$

where: ZML*-function of the concentration degree on the performance cloud peak; $r$ the total number of candidate countries in Europe; $m$ - the number of the candidate countries took into analysis (Serbia and Montenegro); $i$ - the number of performance criteria which lead to economic efficiency; $k$ - the number of criteria which meet the performance specifically analysed; $j$ - the performance achieved by the analysed candidate states.

On the other hand, $(\exists) i_{k}^{* *} \leq(\forall)\left(i_{k}\right)$ and $j_{m}^{* *}\left(i_{k}\right) \leq(\forall) j_{m}\left(i_{k}\right)$ so that the concentration degree function on the lowest limit that allows performance $\left(\mathrm{ZML}^{* *}\right)$ is valid under the following conditions: 


$$
\begin{gathered}
\mathrm{ZML}^{* *}=\frac{\sum_{m=1}^{r} j_{m}}{\sqrt{\frac{\sum_{m=1}^{r} j_{m} \cdot\left[\left|\frac{i_{k}}{\sum_{k=0}^{p} i_{k}}\right|^{2}-1\right]}{\left(\sum_{m=1}^{r} j_{m}\right)-1}}>0 \text { and }} \\
\left\{\begin{array}{c}
\lim _{i \rightarrow \infty}\left(\left|\min \left(i_{k}\right)-\mathrm{ZML}^{* *}\right|\right)=\lim _{i \rightarrow \infty}\left(\left|i_{k}^{* *}-\mathrm{ZML}^{* *}\right|\right) \rightarrow 0 \\
\mathrm{ZML}^{* *} \ll \sum_{k=1}^{p} i_{k} \\
\mathrm{ZML}^{* *} \rightarrow \sum_{k=1}^{p} i_{k} \Leftrightarrow i \rightarrow 1
\end{array}\right.
\end{gathered}
$$

where $\mathrm{ZML}^{* *}$ - concentration degree function on the lowest limit that allows performance.

In order to get the performance profile that any $i_{k}$ would adopt to access the leader's cloud of performance (Germany) and to maximize the economic benefits, the gap.

$$
\Delta=\mathrm{ZML}^{*}-\mathrm{ZML}^{* *}
$$

Is representative for $i_{k}, \alpha_{i_{k}}-\alpha_{\text {leader }}>0$.

The proposed model allows to identify the level of concentration in the leader area using the statistical cloud. It is defined by equation no. 1 and by the item under review position $\left(i_{k}\right)$ in the sample highlighting the difference from leader in equation no. 3 .

This model (ZML) presents direct applicability for the set objectives and the assigned performance criteria. The analysis in this paper uses ZML model to identify the adhering impact on both candidate countries (Serbia and Montenegro), to estimate the degree of concentration with the leading economic entity (Germany) and to quantify the economic viability and the advantages of the integration for the same two economies.

\section{Results}

The economic performances of the above three countries (Germany, Montenegro and Serbia) are analysed, using representative economic indicators, in the following Tables: 2, 3, $4,5,6,7$.

According to data from Table 2, Germany succeeded in maintaining the average economic growth rate during the whole analysed period. The decrease in the indicator values during 2018-2019 can anticipate the beginning of a new economic crisis. Montenegro and Serbia face to different trends for their economic growth rates, but the approach for Serbia is more optimistic.

The comparative distribution of the economic growth rates in both candidate countries and in Germany leads to values above 1 . This means a good integration potential for the analysed candidate countries.

Montenegro realized high gross fixed capital formation rates, while Germany will continue to increase the rates during the forecast period. Serbia maintained constant average values for the same indicator (see Table 3). The high investment rates in Montenegro are supported by two very important infrastructure projects: the power cable with Italy and the highway between Bar and Boljare (European Commission, 2019).

A relative decrease in public consumption rate in Germany is accompanied by a little increase of the indicator in Montenegro and a significant increase in Serbia (see Table 4). The evolution of the public consumption in Serbia is supported by the accumulation of budget associated with fiscal performance in sustainable footing and increased labour absorption. Moreover, Serbia will maintain the actual trend of the public finances through 
Table 2 GDP's trend in Germany and both candidate countries (\%). Source: authors' contribution using https://ec.europa.eu/info/business-economy-euro/economic-performance-and-forecasts/economic-forecasts/ autumn-2020-economic-forecast_en

\begin{tabular}{|c|c|c|c|c|c|c|c|}
\hline GDP & Germany & Montenegro & $\begin{array}{l}\text { Montenegr/Ger- } \\
\text { many }\end{array}$ & $P$-value & Serbia & Serbia/Germany & $P$-value \\
\hline 2014 & 1.3 & 3.4 & $261.54 \%$ & $<0.001$ & 0.8 & $61.54 \%$ & $<0.001$ \\
\hline 2015 & 1.7 & 3.4 & $200.00 \%$ & $<0.001$ & 0.8 & $47.06 \%$ & $<0.001$ \\
\hline 2016 & 2.2 & 2.9 & $131.82 \%$ & $<0.001$ & 2.8 & $127.27 \%$ & $<0.001$ \\
\hline 2017 & 2.2 & 4.7 & $213.64 \%$ & $<0.001$ & 1.9 & $86.36 \%$ & $<0.001$ \\
\hline 2018 & 1.7 & 3.9 & $229.41 \%$ & $<0.001$ & 4.1 & $241.18 \%$ & $<0.001$ \\
\hline 2019 & 1.8 & 2.8 & $155.56 \%$ & $<0.001$ & 3.8 & $211.11 \%$ & $<0.001$ \\
\hline $\begin{array}{l}\text { Average } \\
\text { 2014-2019 }\end{array}$ & 1.8 & 3.5 & $198.66 \%$ & $<0.001$ & 2.4 & $129.09 \%$ & $<0.001$ \\
\hline 2020 & 1.7 & 3.1 & $182.35 \%$ & $<0.001$ & 3.8 & $223.53 \%$ & $<0.001$ \\
\hline 2021 & 1.8 & 3.4 & $188.89 \%$ & $<0.001$ & 4.8 & $266.67 \%$ & $<0.001$ \\
\hline 2022 & 1.8 & 3.4 & $188.89 \%$ & $<0.001$ & 5.4 & $300.00 \%$ & $<0.001$ \\
\hline 2023 & 1.8 & 3.4 & $188.89 \%$ & $<0.001$ & 6 & $333.33 \%$ & $<0.001$ \\
\hline 2024 & 1.8 & 3.4 & $188.89 \%$ & $<0.001$ & 6.6 & $366.67 \%$ & $<0.001$ \\
\hline 2025 & 1.8 & 3.4 & $188.89 \%$ & $<0.001$ & 7.2 & $400.00 \%$ & $<0.001$ \\
\hline $\begin{array}{l}\text { Average simple } \\
\text { forecast } \\
2020-2025\end{array}$ & 1.8 & 3.4 & $187.80 \%$ & $<0.001$ & 5.6 & $315.03 \%$ & $<0.001$ \\
\hline
\end{tabular}

Table 3 GFC's trend in Germany and both candidate countries (\%). Source:authors' contribution using https://ec.europa.eu/info/business-economy-euro/economic-performance-and-forecasts/economic-forecasts/ autumn-2020-economic-forecast_en

\begin{tabular}{llllllll}
\hline GFC & Germany & Montenegro & $\begin{array}{l}\text { Montenegro/ } \\
\text { Germany }\end{array}$ & $P$-value & Serbia & Serbia/Germany & $P$-value \\
\hline 2014 & 0.9 & 11.9 & $1322.22 \%$ & $<0.001$ & 5.6 & $622.22 \%$ & $<0.001$ \\
2015 & 1.6 & 11.9 & $743.75 \%$ & $<0.001$ & 5.6 & $350.00 \%$ & $<0.001$ \\
2016 & 3.5 & 38.4 & $1097.14 \%$ & $<0.001$ & 5.1 & $145.71 \%$ & $<0.001$ \\
2017 & 2.9 & 18.7 & $644.83 \%$ & $<0.001$ & 6.2 & $213.79 \%$ & $<0.001$ \\
2018 & 3.1 & 17.7 & $570.97 \%$ & $<0.001$ & 11.3 & $364.52 \%$ & $<0.001$ \\
2019 & 2.9 & 11.2 & $386.21 \%$ & $<0.001$ & 7.4 & $255.17 \%$ & $<0.001$ \\
Average & 2.5 & 18.3 & $794.19 \%$ & $<0.001$ & 6.9 & $325.24 \%$ & $<0.001$ \\
$2014-2019$ & & & & & & & $<0.001$ \\
2020 & 3.2 & 9.1 & $284.38 \%$ & $<0.001$ & 7.3 & $228.13 \%$ & $<0.001$ \\
2021 & 3.8 & 16.1 & $423.68 \%$ & $<0.001$ & 6.9 & $181.58 \%$ & $<0.001$ \\
2022 & 4.1 & 16.1 & $392.68 \%$ & $<0.001$ & 6.9 & $168.29 \%$ & $<0.001$ \\
2023 & 4.5 & 16.1 & $357.78 \%$ & $<0.001$ & 6.9 & $153.33 \%$ & $<0.001$ \\
2024 & 4.8 & 16.1 & $335.42 \%$ & $<0.001$ & 6.9 & $143.75 \%$ & $<0.001$ \\
2025 & 5.1 & 16.1 & $315.69 \%$ & $<0.001$ & 6.9 & $135.29 \%$ & $<0.001$ \\
Average simple & 4.3 & 14.9 & $351.60 \%$ & $<0.001$ & 7.0 & $168.40 \%$ & \\
forecast & & & & & & & \\
$2020-2025$ & & & & & & & \\
\hline & & & & & & & \\
\hline
\end{tabular}


Table 4 PC's trend in Germany and both candidate countries (\%). Source:authors' contribution using https://ec.europa.eu/info/business-economy-euro/economic-performance-and-forecasts/economic-forecasts/ autumn-2020-economic-forecast_en

\begin{tabular}{llcccccc}
\hline PC & Germany & Montenegro & $\begin{array}{l}\text { Montenegro/ } \\
\text { Germany }\end{array}$ & $P$-value & Serbia & Serbia/Germany & $P$-value \\
\hline 2014 & 1.2 & 1.9 & $158.33 \%$ & $<0.001$ & -1.5 & $-125.00 \%$ & $<0.001$ \\
2015 & 2.9 & 1.9 & $65.52 \%$ & $<0.001$ & -1.5 & $-51.72 \%$ & $<0.001$ \\
2016 & 4 & 0.8 & $20.00 \%$ & $<0.001$ & 2.2 & $55.00 \%$ & $<0.001$ \\
2017 & 1.6 & -1.4 & $-87.50 \%$ & $<0.001$ & 1 & $62.50 \%$ & $<0.001$ \\
2018 & 1.3 & 1.6 & $123.08 \%$ & $<0.001$ & 3.7 & $284.62 \%$ & $<0.001$ \\
2019 & 2.3 & 1.7 & $73.91 \%$ & $<0.001$ & 3.5 & $152.17 \%$ & $<0.001$ \\
Average & 2.2 & 1.1 & $58.89 \%$ & $<0.001$ & 1.2 & $62.93 \%$ & $<0.001$ \\
$2014-2019$ & & & & & & & \\
2020 & 1.7 & 1.9 & $111.76 \%$ & $<0.001$ & 3.5 & $205.88 \%$ & $<0.001$ \\
2021 & 2.1 & 1.2 & $57.14 \%$ & $<0.001$ & 5.2 & $247.62 \%$ & $<0.001$ \\
2022 & 2.1 & 1.2 & $57.14 \%$ & $<0.001$ & 6.2 & $295.24 \%$ & $<0.001$ \\
2023 & 2.1 & 1.2 & $57.14 \%$ & $<0.001$ & 7.1 & $338.10 \%$ & $<0.001$ \\
2024 & 2.1 & 1.2 & $57.14 \%$ & $<0.001$ & 8.1 & $385.71 \%$ & $<0.001$ \\
2025 & 2.1 & 1.2 & $57.14 \%$ & $<0.001$ & 9 & $428.57 \%$ & $<0.001$ \\
Average simple & 2.0 & 1.3 & $66.25 \%$ & $<0.001$ & 6.5 & $316.85 \%$ & $<0.001$ \\
forecast & & & & & & & \\
$2020-2025$ & & & & & & & \\
\hline
\end{tabular}

Table 5 Unemployment's trend in Germany and both candidate countries (\%). Source:authors' contribution using https://ec.europa.eu/info/business-economy-euro/economic-performance-and-forecasts/economicforecasts/autumn-2020-economic-forecast_en

\begin{tabular}{llllllll}
\hline UNE & Germany & Montenegro & $\begin{array}{l}\text { Germany/ } \\
\text { Montene- } \\
\text { gro }\end{array}$ & $P$-value & Serbia & Germany/Serbia & $P$-value \\
\hline 2014 & 7.9 & 17.6 & $44.89 \%$ & $<0.001$ & 17.7 & $44.63 \%$ & $<0.001$ \\
2015 & 4.6 & 17.6 & $26.14 \%$ & $<0.001$ & 17.7 & $25.99 \%$ & $<0.001$ \\
2016 & 4.1 & 17.7 & $23.16 \%$ & $<0.001$ & 15.3 & $26.80 \%$ & $<0.001$ \\
2017 & 3.8 & 16.1 & $23.60 \%$ & $<0.001$ & 13.6 & $27.94 \%$ & $<0.001$ \\
2018 & 3.5 & 15.5 & $22.58 \%$ & $<0.001$ & 13.1 & $26.72 \%$ & $<0.001$ \\
2019 & 3.2 & 14.9 & $21.48 \%$ & $<0.001$ & 12 & $26.67 \%$ & $<0.001$ \\
Average 2014-2019 & 4.5 & 16.6 & $26.97 \%$ & $<0.001$ & 14.9 & $29.79 \%$ & $<0.001$ \\
2020 & 3 & 14.6 & $20.55 \%$ & $<0.001$ & 10.9 & $27.52 \%$ & $<0.001$ \\
2021 & 2.8 & 13.9 & $20.14 \%$ & $<0.001$ & 9.5 & $29.47 \%$ & $<0.001$ \\
2022 & 2.6 & 13.3 & $19.55 \%$ & $<0.001$ & 8.3 & $31.33 \%$ & $<0.001$ \\
2023 & 2.4 & 12.8 & $18.75 \%$ & $<0.001$ & 7.1 & $33.80 \%$ & $<0.001$ \\
2024 & 2.2 & 12.2 & $18.03 \%$ & $<0.001$ & 5.9 & $37.29 \%$ & $<0.001$ \\
2025 & 2 & 11.6 & $17.24 \%$ & $<0.001$ & 4.7 & $42.55 \%$ & $<0.001$ \\
Average sim- & 2.5 & 13.1 & $19.04 \%$ & $<0.001$ & 7.7 & $33.66 \%$ & $<0.001$ \\
ple forecast & & & & & & & \\
$2020-2025$ & & & & & & & \\
\hline
\end{tabular}


Table 6 HICP's trend in Germany and both candidate countries (\%). Source:authors' contribution using https://ec.europa.eu/info/business-economy-euro/economic-performance-and-forecasts/economic-forecasts/ autumn-2020-economic-forecast_en

\begin{tabular}{llcccccc}
\hline HICP & Germany & Montenegro & $\begin{array}{l}\text { Germany/ } \\
\text { Montene- } \\
\text { gro }\end{array}$ & $P$-value & Serbia & Germany/Serbia & $P$-value \\
\hline 2014 & 1.6 & 1.4 & $114.29 \%$ & $<0.001$ & 1.4 & $114.29 \%$ & $<0.001$ \\
2015 & 0.1 & 1.4 & $7.14 \%$ & $<0.001$ & 1.4 & $7.14 \%$ & $<0.001$ \\
2016 & 0.4 & 0.1 & $400.00 \%$ & $<0.001$ & 1.1 & $36.36 \%$ & $<0.001$ \\
2017 & 1.7 & 2.8 & $60.71 \%$ & $<0.0013 .2$ & $53.13 \%$ & $<0.001$ \\
2018 & 1.8 & 2.9 & $62.07 \%$ & $<0.0012 .1$ & $85.71 \%$ & $<0.001$ \\
2019 & 1.9 & 2.5 & $76.00 \%$ & $<0.0012 .9$ & $65.52 \%$ & $<0.001$ \\
Average 2014-2019 & 1.3 & 1.9 & $120.04 \%$ & $<0.0012 .0$ & $60.36 \%$ & $<0.001$ \\
2020 & 1.6 & 1.9 & $84.21 \%$ & $<0.0013$ & $53.33 \%$ & $<0.001$ \\
2021 & 1.3 & 1.9 & $68.42 \%$ & $<0.0013 .3$ & $39.39 \%$ & $<0.001$ \\
2022 & 1.3 & 1.9 & $68.42 \%$ & $<0.0013 .6$ & $36.11 \%$ & $<0.001$ \\
2023 & 1.3 & 1.9 & $68.42 \%$ & $<0.0013 .9$ & $33.33 \%$ & $<0.001$ \\
2024 & 1.3 & 1.9 & $68.42 \%$ & $<0.0014 .2$ & $30.95 \%$ & $<0.001$ \\
2025 & 1.3 & 1.9 & $68.42 \%$ & $<0.0014 .6$ & $28.26 \%$ & $<0.001$ \\
Average sim- & 1.4 & 1.9 & $71.05 \%$ & $<0.0013 .8$ & $36.90 \%$ & $<0.001$ \\
ple forecast & & & & & & & \\
$2020-2025$ & & & & & & & \\
\hline
\end{tabular}

Table 7 Gross government debt's trend in Germany and both candidate countries (\%). Source:authors' contribution using https://ec.europa.eu/info/business-economy-euro/economic-performance-and-forecasts/ economic-forecasts/autumn-2020-economic-forecast_en

\begin{tabular}{|c|c|c|c|c|c|c|c|}
\hline GGGD & Germany & Montenegro & $\begin{array}{l}\text { Germany/ } \\
\text { Montene- } \\
\text { gro }\end{array}$ & $P$-value & Serbia & Germany/Serbia & $P$-value \\
\hline 2014 & 68.1 & 62.3 & $109.31 \%$ & $<0.001$ & 74.6 & $91.29 \%$ & $<0.001$ \\
\hline 2015 & 70.8 & 62.3 & $113.64 \%$ & $<0.001$ & 74.6 & $94.91 \%$ & $<0.001$ \\
\hline 2016 & 67.9 & 64.4 & $105.43 \%$ & $<0.001$ & 72.5 & $93.66 \%$ & $<0.001$ \\
\hline 2017 & 63.9 & 63.7 & $100.31 \%$ & $<0.001$ & 61.6 & $103.73 \%$ & $<0.001$ \\
\hline 2018 & 60.1 & 70 & $85.86 \%$ & $<0.001$ & 56.4 & $106.56 \%$ & $<0.001$ \\
\hline 2019 & 56.7 & 67.8 & $83.63 \%$ & $<0.001$ & 54.1 & $104.81 \%$ & $<0.001$ \\
\hline Average 2014-2019 & 64.6 & 65.1 & $99.70 \%$ & $<0.001$ & 65.6 & $99.16 \%$ & $<0.001$ \\
\hline 2020 & 53.7 & 62.7 & $85.65 \%$ & $<0.001$ & 52.1 & $103.07 \%$ & $<0.001$ \\
\hline 2021 & 50.7 & 64.7 & $78.36 \%$ & $<0.001$ & 48.3 & $104.97 \%$ & $<0.001$ \\
\hline 2022 & 47.7 & 64.7 & $73.72 \%$ & $<0.001$ & 44.6 & $106.95 \%$ & $<0.001$ \\
\hline 2023 & 44.7 & 64.7 & $69.09 \%$ & $<0.001$ & 40.8 & $109.56 \%$ & $<0.001$ \\
\hline 2024 & 41.7 & 64.7 & $64.45 \%$ & $<0.001$ & 37.1 & $112.40 \%$ & $<0.001$ \\
\hline 2025 & 38.7 & 64.7 & $59.81 \%$ & $<0.001$ & 33.3 & $116.22 \%$ & $<0.001$ \\
\hline $\begin{array}{l}\text { Average sim- } \\
\text { ple forecast } \\
2020-2025\end{array}$ & 46.2 & 64.4 & $71.85 \%$ & $<0.001$ & 42.7 & $108.86 \%$ & $<0.001$ \\
\hline
\end{tabular}


the long-term implementation of reforms in administration and finance and by completing the process of restructuring and privatizing public companies.

The above three economic indicators point out the general favouring integration trend and demonstrate that both analysed candidate countries have capacities that can be positively capitalized on the integration process, with positive impact on EU economy.

During the forecast period, the average unemployment rate will be close to the equilibrium rate in EU. Montenegro and Serbia face to greater unemployment rates (see Table 5).

Serbia will face to greater inflation which will be supported by strong domestic demand and worsening terms of trade. During 2017-2019, inflation grew in Montenegro as a result of increasing tobacco and fuels' prices. On the other hand, inflation is forecast to decline slightly afterwards. Germany will succeed to stabilize the inflation level during the forecast period (see Table 6).

The economic performance of the German economy is the main element in decreasing gross government debts during the whole analysed period. Serbia will obtain better results in decreasing the same debts. These results came from the general government budget surplus at the beginning of the forecast period. Montenegro faced to a peak public debt in 2018 as a result of an emission of Eurobonds and a credit arrangement with commercial banks in order to reduce the refinancing risks on medium term. During the forecast period, the same debt rate will decrease thanks to fast nominal GDP growth (see Table 7).

The calculation in the table covers the following steps:

Column $1 \frac{j_{m}}{\sum_{m=0}^{r} j_{m}}$; Column $2\left(\frac{j_{m}}{\sum_{m=0}^{r} j_{m}}\right)^{2}$; Column $31-\left(\frac{i_{k}}{\sum_{k=0}^{p} i_{k}}\right)^{2}$;

Column $4 \sum\left(1-\left(\frac{j_{m}}{\sum_{m=0}^{r} j_{m}}\right)^{2}\right)$; Column $5 \frac{i_{k}}{\sum_{k=0}^{p} i_{k}}$; Column $6\left(\frac{i_{k}}{\sum_{k=0}^{p} i_{k}}\right)^{2}$;

Column $71-\left(\frac{i_{k}}{\sum_{k=0}^{p} i_{k}}\right)^{2}$

Column $8 \sum\left(1-\left(\frac{i_{k}}{\sum_{k=0}^{p} i_{k}}\right)^{2}\right)$

Column 9ZML ${ }^{*}=\frac{\sum_{m=1}^{r} j_{m}}{\sqrt{\frac{\sum_{m=1}^{r} j_{m} \cdot\left[1-\left(\frac{i_{k}}{\Sigma_{k=0}^{p} i_{k}}\right)^{2}\right]}{\left(\sum_{m=1}^{r} j_{m}\right)^{-1}}}}$ Column $10 \lim _{i \rightarrow \infty}\left(\left|\max \left(i_{k}\right)-Z M L^{*}\right|\right)$.

The above algorithm is used for all following tables in the paper (Tables 8-19). The applying of the ZML theorem on Serbia's GDP trends in connection to the EU27 leader Germany points out that the candidate country will have a positive potential of economic growth after its adhering. This conclusion is based on the comparative analysis between the forecast economic growth trend and the economic growth trend during 2014-2019.

The applying of the theorem limit formula indicates that the obtained values are higher in the particular case of the integration model. This confirms the comparative advantage of the Serbian economy related to GDP growth (see Table8).

The applying of the ZML theorem on Montenegro's GDP trends in connection to the EU27 leader Germany points out that the candidate country has a lower potential for the EU economic growth after its adhering. This conclusion is supported by the analysis of the forecast trend and the realized trend during 2014-2019 (see Table9).

The applied theorem to the model of economic growth points out the advantage of the integration after calculating the proposed limit in the theorem (see columns 8 and 9 from Table 10). An effect of the integration will be the improvement of the GFC values by adopting common policies related to sustainable development and economic efficiency promoted in the EU. Other significant positive element for Serbia is the access to the European funding programmes through structural funds. These funds will create 


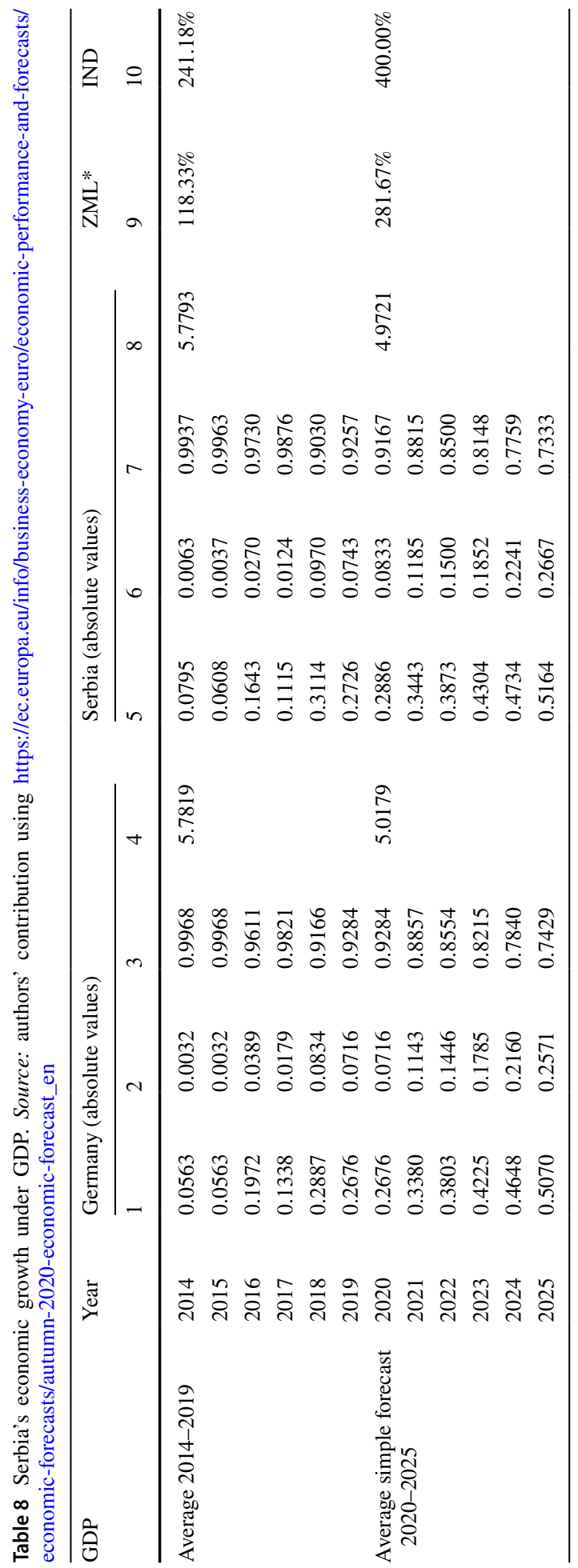




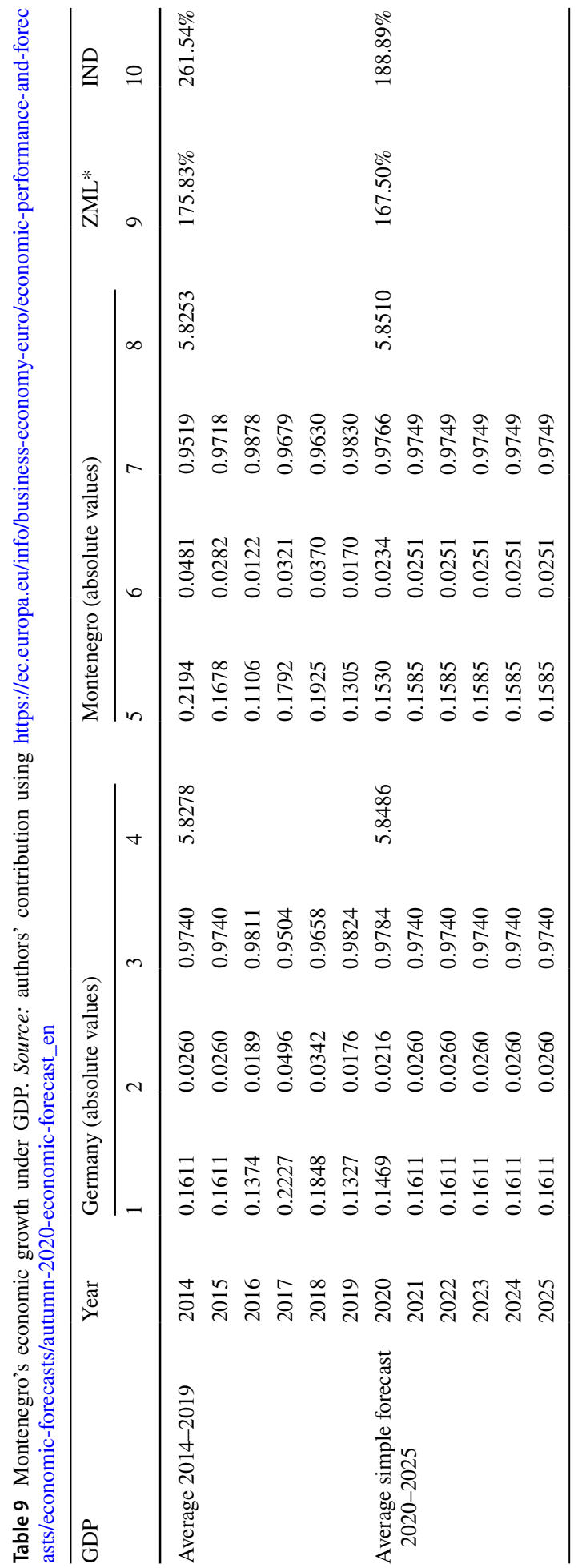




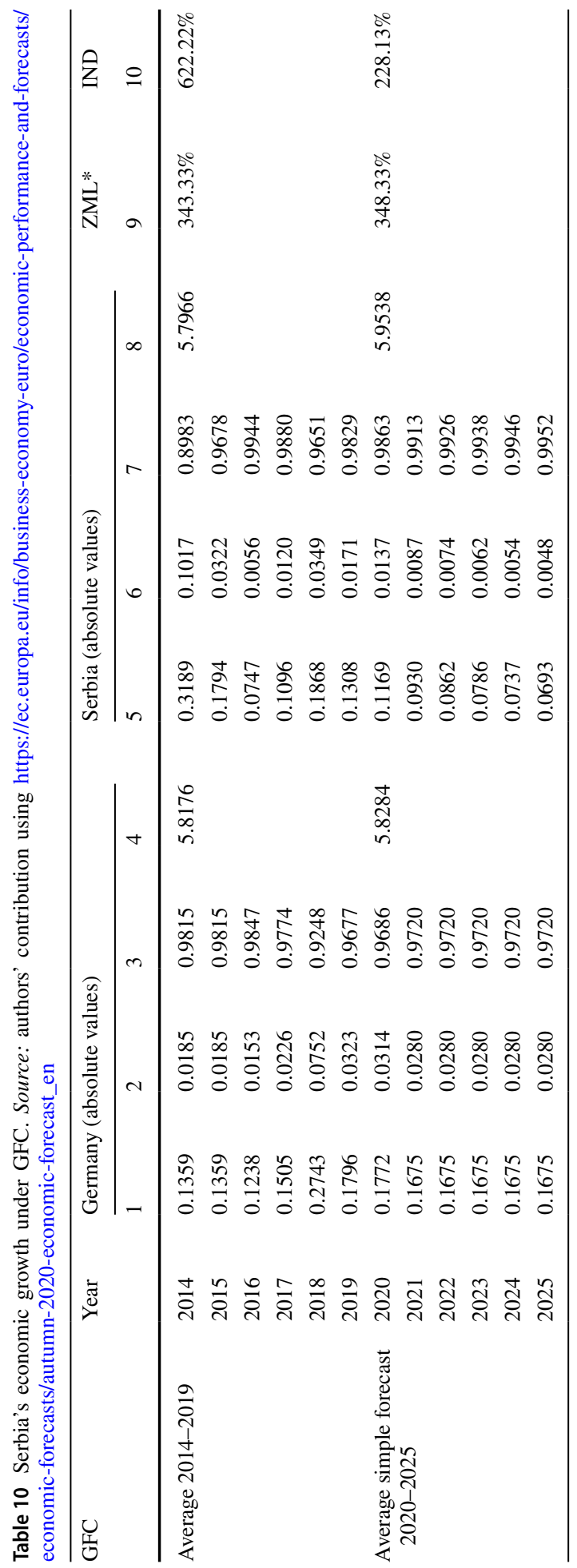


the prerequisites for Serbia's economic cohesion with the EU. The gap to the leader is significant, but the trend reversal will bring about an improvement in the economic situation after accession through its positive effects (see Table 10).

The economic growth in Montenegro under the GFC has the same trend as in Serbia. The trend related to 2014-2019 exceeds the trend calculated by the ZML model. During 2020-2025, the ZML trend is higher than the individual trend. The cumulative effect will favourable evolutions of the indicator under the conditions imposed by the accession (see Table 11).

The public consumption is an indirectly proportional variable to the accession projected growth. The candidate countries need additional funds to create cohesion mechanisms at national level. For Serbia and Montenegro, the applying the theorem reveals that the individual trend is superior to the trend calculated by the theorem. Moreover, the deviations (gaps) from the leader (Germany) are great and very great. During 2014-2019, both candidate countries record an individual trend above the trend calculated by the theorem. This process will grow during the forecast period by increasing the distance from the leader and taking into account the pre-accession forecast (see Tables 12, 13).

From the economic growth's point of view, the public consumption (PC) represents a critical indicator which has to be carefully monitored during the pre-accession period. PC can significantly disrupt the budget execution of the two candidate countries under the impact of the cohesion measures related to the building of the single market specific infrastructure.

The unemployment rate (UNE) under European integration is analysed in terms of its effect on the economy (limiting the development of the phenomenon through mechanisms of labour integration and social inclusion). For both candidate countries, the individual trend is higher than the trend calculated by the theorem. The impact on the labour market will be negative after adhering as a result of the increasing in requirements for labour force qualification and the changing the labour supply structure (see Tables 14, 15).

On average term, the European financing programmes will support the unemployment decreasing and social disparities mitigating. Other element is the opening of the EU market for specialists from both candidate countries. An open labour market will reduce unemployment but will increase the specialists' migration from the candidate countries to the most developed Member States.

Inflation represents a special case cross the above six analysed indicators in this paper. For both candidate countries, the individual forecasted trend is almost the same to the trend calculated by the theorem. This means that the adhering process has a powerful positive impact on inflation because the EU's force will tend to neutralize the national gaps in the field (see Tables 16, 17).

Single currency protectionism influences the candidate countries' monetary policies, which are forced by the adhering mechanisms to stabilize inflation and to correlate it to the EU average.

The level of general governmental gross debt (GGGD) directly reflects the financial strength of the candidate countries. The domestic mechanisms for balancing payments are deeply disturbed after the adhering moment $T_{0}$ through the liberalization of European trade in the candidate countries and the cohesion commitments assumed by accession. The gap of the individual indicator to the indicator calculated by the theorem is maximal (see Tables 17, 18).

Polarization towards the leader (Germany) is significant, because the economic leader will benefit directly from the competitive advantage. As a result, Germany will directly 


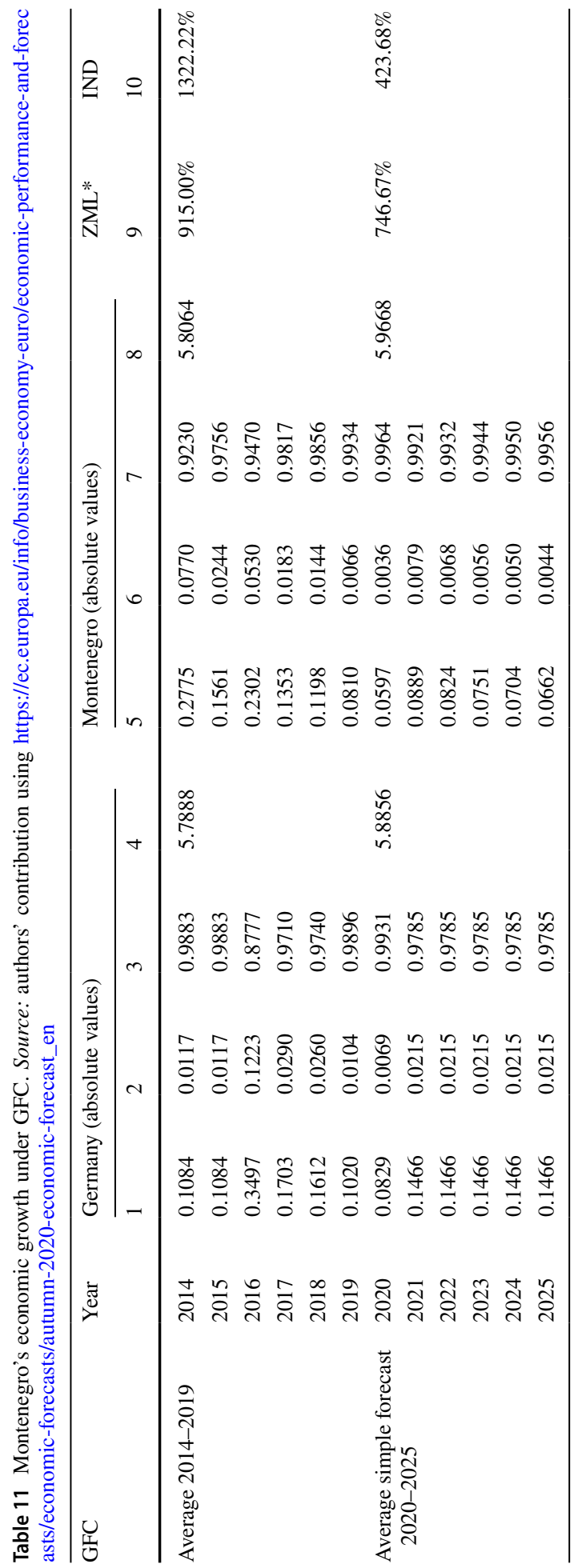




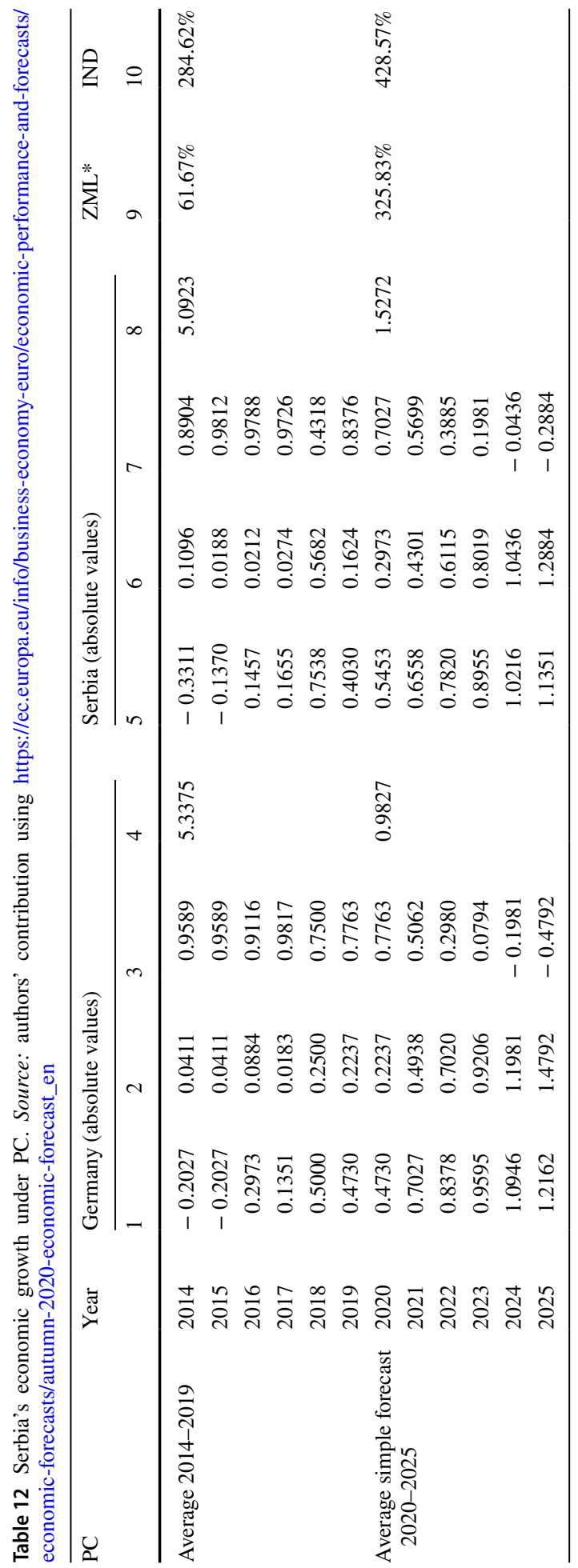




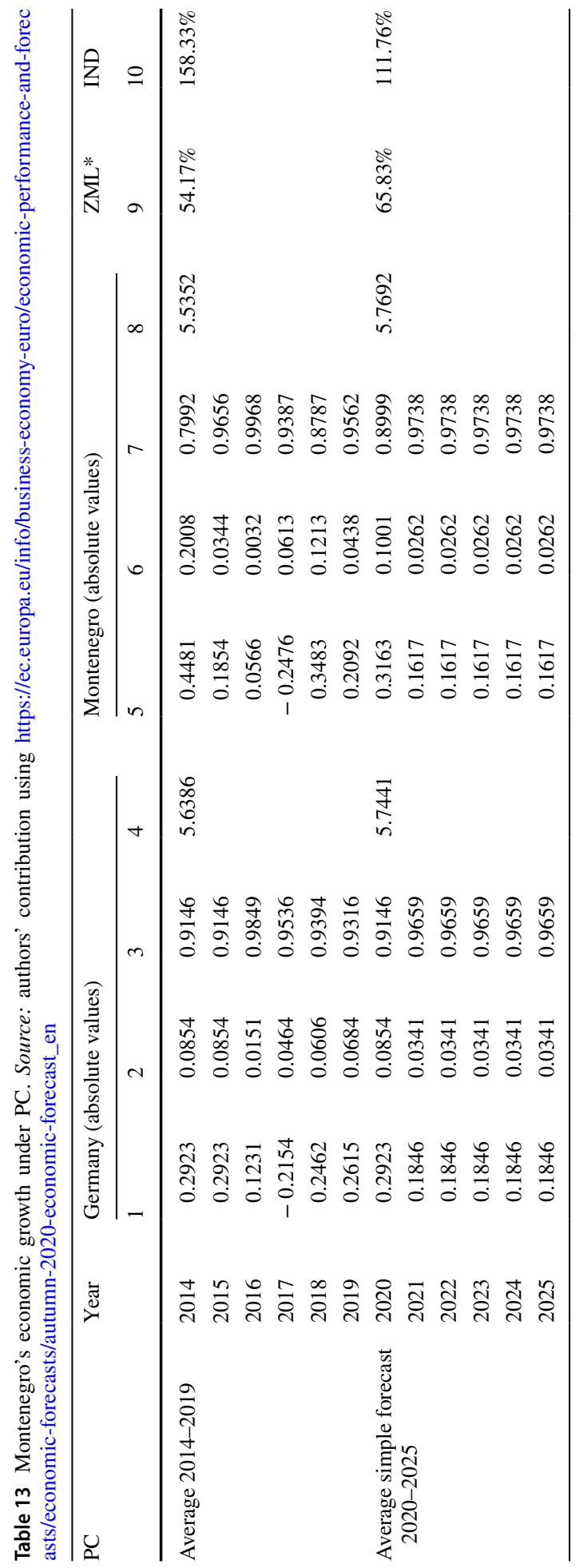




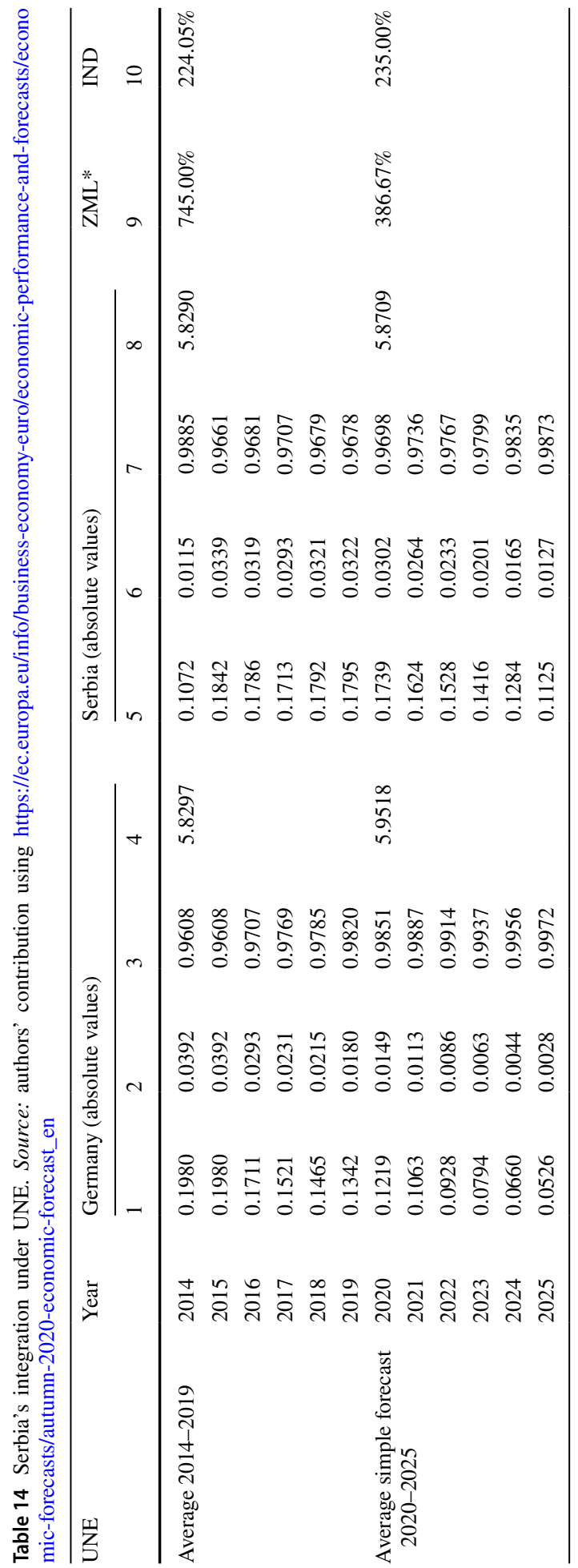




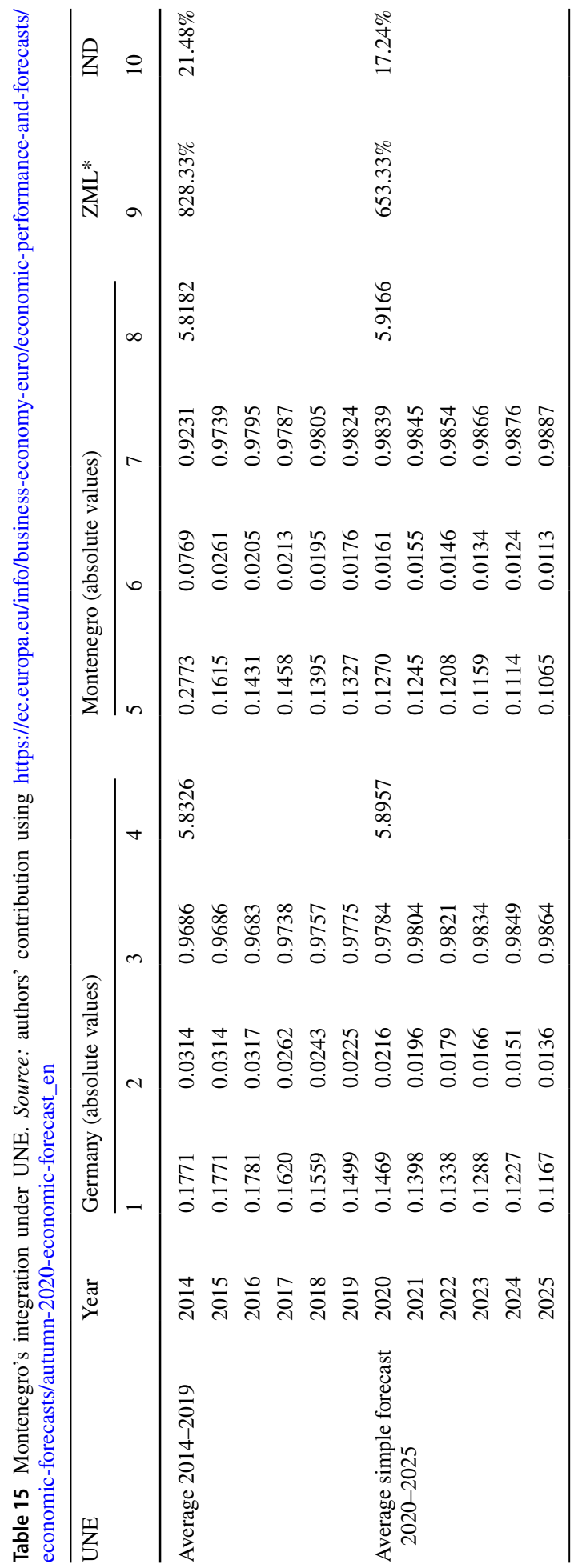




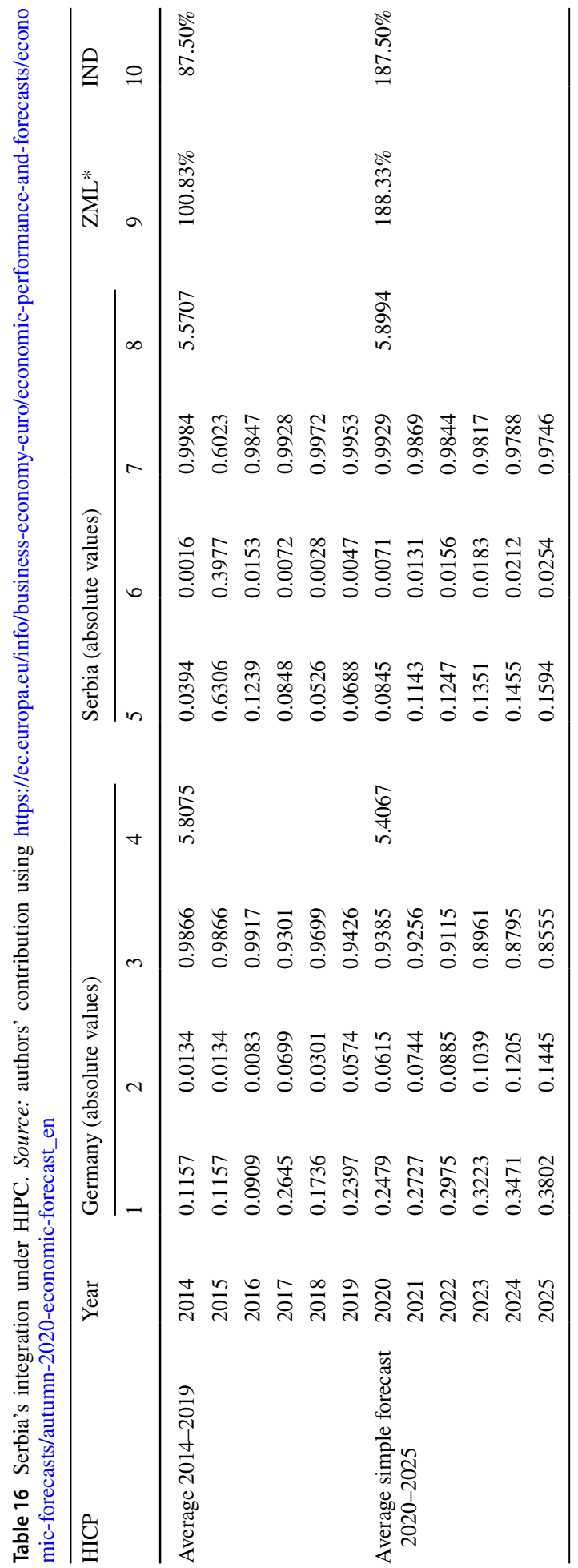




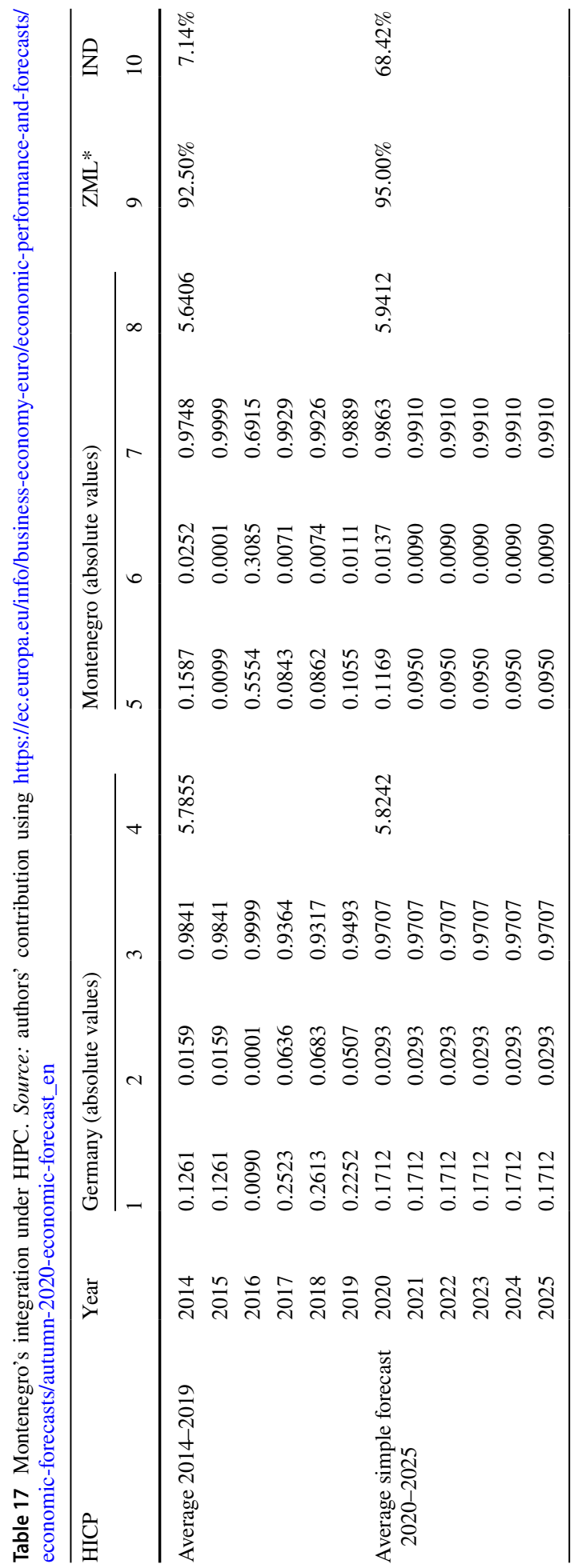




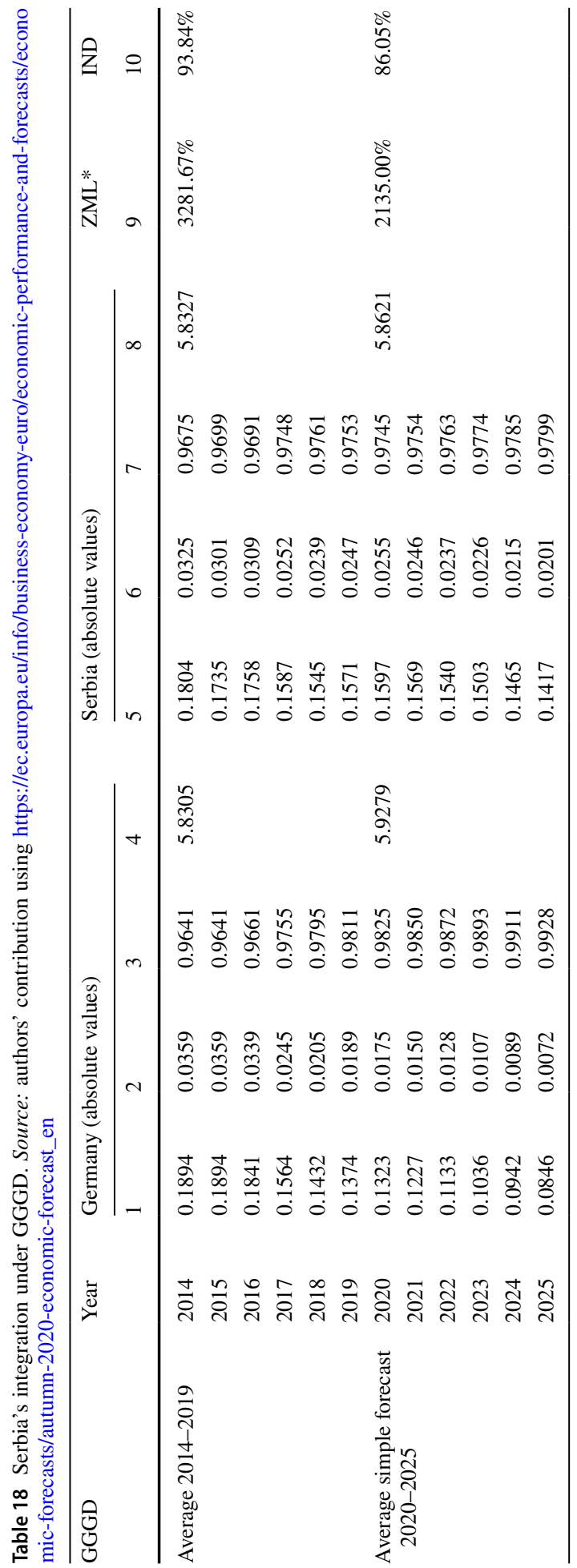


increase its economic benefits by free exports to the new member states after their adhering.

\section{Discussion}

The above analysis is represented schematically at the growth/integration flow level as in Table 20.

Serbia's competitive advantage regarding GDP points out a minimal implication of the European bodies in adopting economic growth policies after adhering. The calculated scorings by summing individual deviations on the average trend of 2014-2019 and the average forecasted trend during 2020-2025 show a reversal in terms of leadership advantage for Serbia (which drops by 0.4 units) as a result of the adhering costs. This decrease points out the polarization gap of the performance cloud in the area of high significance. This means that Serbia would adopt economic policy measures to protect the GDP balance in budget execution before adhering. This goal can be achieved using the foreign capital and investment (see Fig. 4).

Montenegro faces to a disadvantage linked to GDP growth during 2020-2025. The calculated scorings by summing individual deviations on the average trend 2014-2019 and the average forecasted trend during 2020-2025 support the gap between Germany and Montenegro as a result of the adhering costs. As a result, Montenegro has to adopt the same as Serbia during the adhering period.

Under GFC, the individual value is higher than that calculated by the theorem in both candidate countries (Serbia and Montenegro). This indicator points out the gap between the reference economy (Germany) and both candidate countries.

The public consumption will have a normal trend during 2020-2025 in Serbia. Montenegro will face to a decrease of this consumption during the forecasted period.

From the integration's point of view, the unemployment rate will decrease in both countries during 2020-2025. On the other hand, the differences between the unemployment rate in Germany and in both candidate countries are too high.

Inflation will decrease during 2020-2025 under the candidate countries' efforts to align to the European average of the indicator.

The integration will bring positive effects on GGGD in Serbia, and Montenegro will succeed a significant decrease of this indicator at the end of the forecasted period (see Fig. 4 and Fig. 5).

The theorem's application on Serbia and Montenegro allows to demonstrate the model hypothesis on two proposed directions: growth and integration.

$H 1, H 2$ : The growth model demonstrates the added value of EU integration for Serbia and Montenegro, especially on the social segment, by increasing employment opportunities in new professions specific to the European market (the creation of European cohesion and adhering structures for each candidate country). Another aspect is the stability advantage by decreasing inflation and strengthening the exchange rate. The critical point is highlighted by the adhering costs and by the necessity of adopting sustainable policies during the pre-adhering period.

$H 3, H 4$. In the context of integration, the study hypotheses related to the inflection point are demonstrated. The positive evolution of the budget execution indicators in Table 19 points out that they have optimal sensitivity for both candidate countries. 


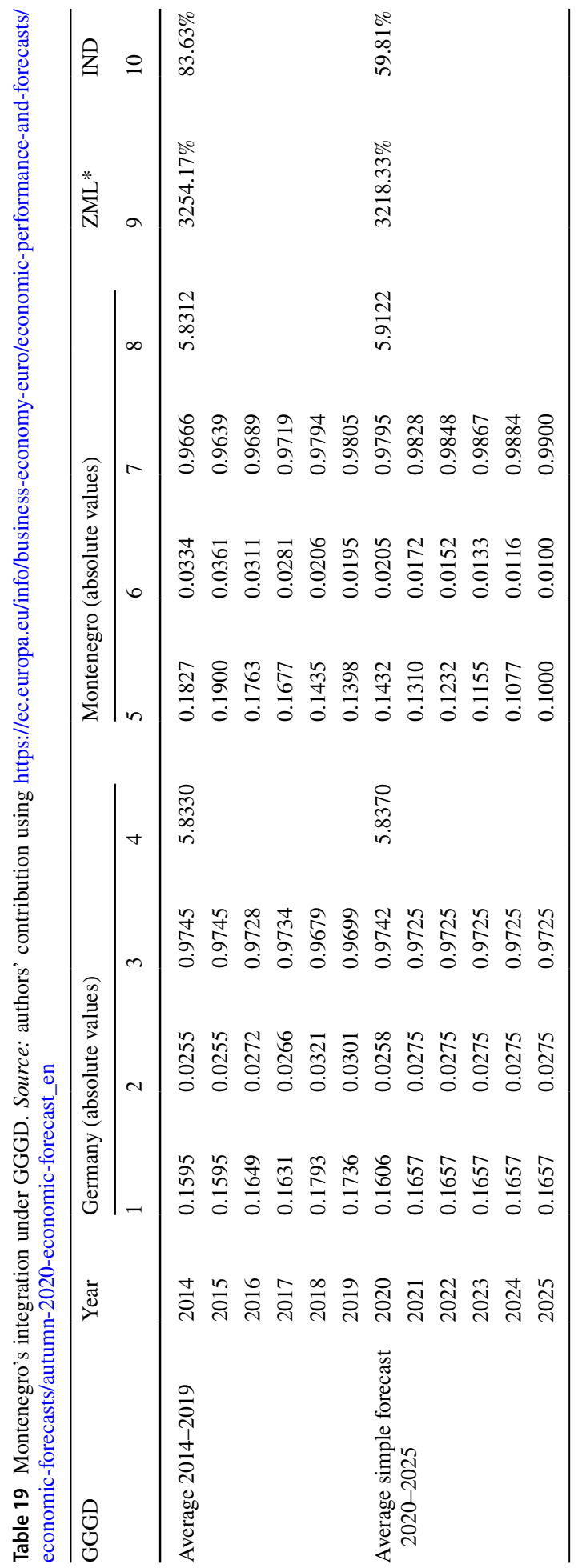




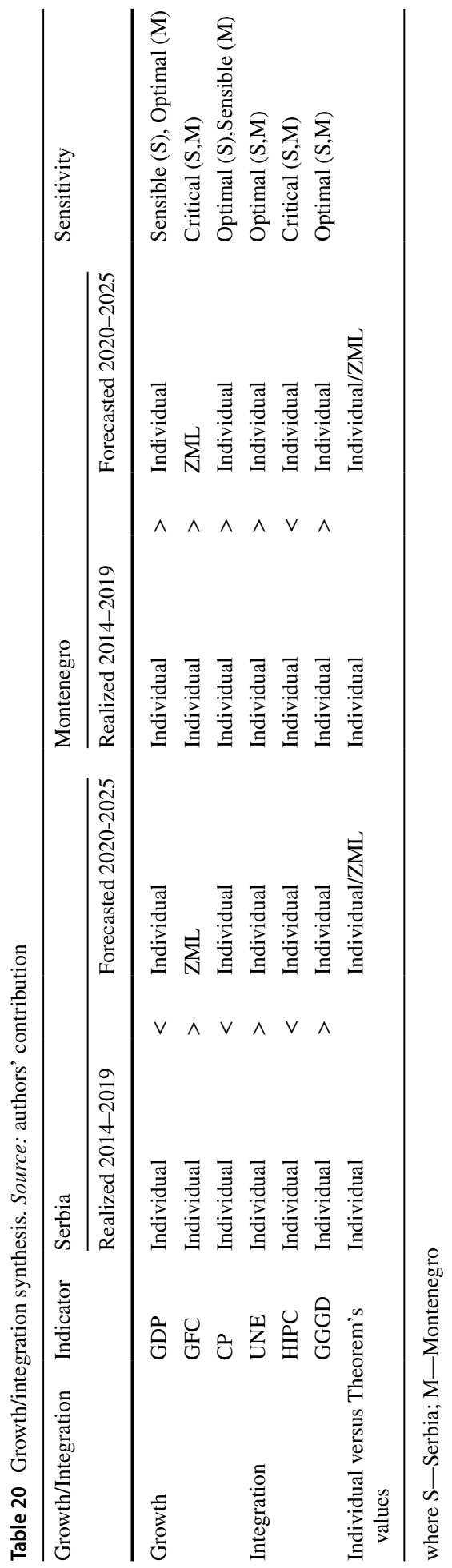




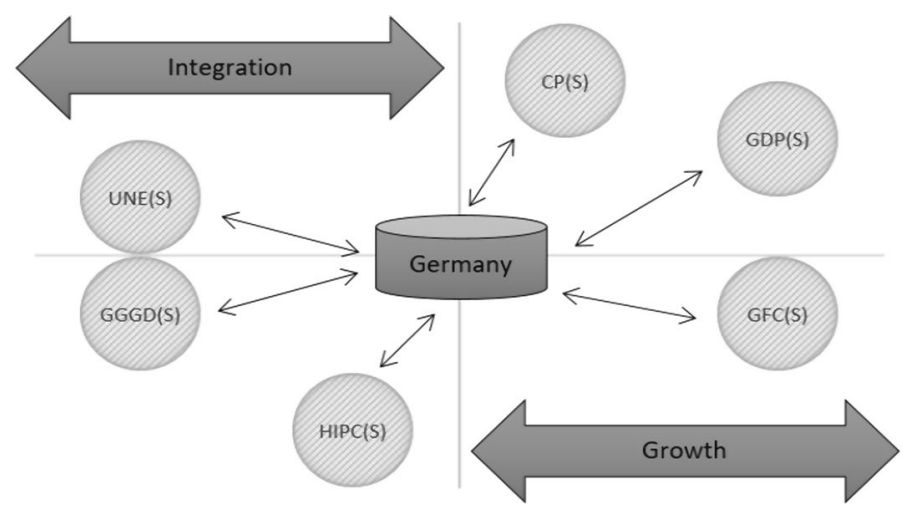

Fig. 4 ZML theory's impact on Serbia's growth and integration. Source:authors' contribution

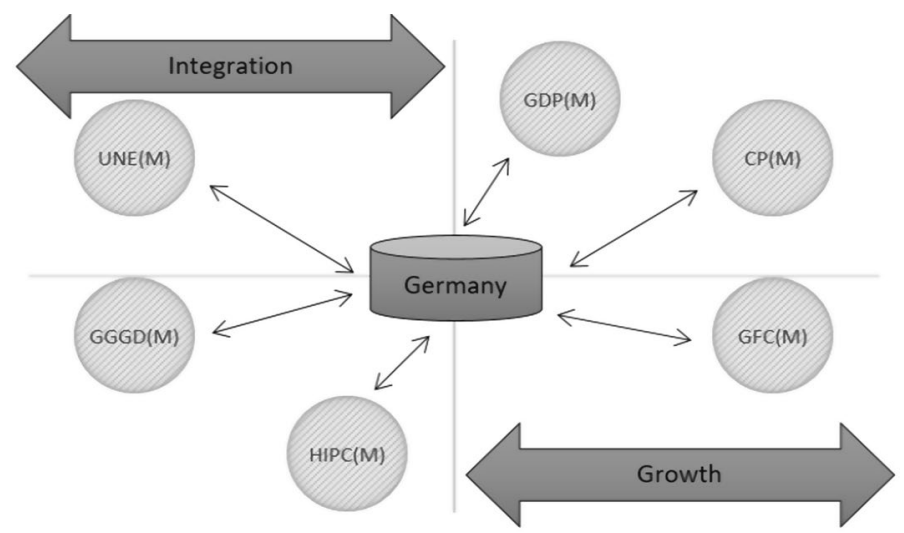

Fig. 5 ZML theory's impact on Montenegro's growth and integration. Source:authors' contribution

\section{Conclusions}

The applied model in this paper represents a radiography of the candidate countries' adhering process. The euro area has impact on them, including the gap to the leader (Germany). The model was tested for six macroeconomic indicators grouped into two categories (growth and integration). Their statistical meaning was computed using p-value. Moreover, their sensitivity was demonstrated after applying the terms of the ZML theorem.

Our approach brings a surplus of knowledge in the field, performing a meta-analysis that dynamizes the old approaches in the current context, classifying the consecrated theories according to their approach level to the current issues. The proposed study and model can be adapted to any economic entity and regional organization that intends to become part of a stratified core such as the EU27, requiring convergence measures of the economic growth policies in relation to the requirements of the stratified core.

The limits of the model consist in the number of indicators taken into account and in the relatively limited period established in relation to the terms of accession of the two candidate states. This does not mean that the model cannot be extended to more indicators. As a result, the authors intend to extend the research to other candidate countries for the EU membership. 
The study is useful for the macro and regional decision-makers, which can forecast the integration efforts under a dynamic approach. Indirectly, the same decision-makers can quantify the adhering efforts under sustainable policies by decreasing the gap to the EU's economic leader (Germany).

\section{Declarations}

Conflict of interest The authors declare that they do not have any conflict of interest.

\section{References}

Barro, R. J., \& Sala-i-Martin, X. (2004). Economic growth. The MIT Press.

Benz, S., Larch, M. \& Zimmer, M. (2014). Trade in ideas: Outsourcing and knowledge spillovers, Ifo Working Paper, No. 173, pp 1-23.

Bonga-Bonga, L. (2017). Assessing the effectiveness of the monetary policy instrument during the inflation targeting period in south africa. International Journal of Economics and Financial Issues, Econjournals, 7(4), 706-713.

Coccia, M. (2018). An introduction to the theories of national and regional economic development. Turkish Economic Review, 5(4), 350-358.

Colin, D., \& Hashimoto, K. (2016). Industry concentration, knowledge diffusion and economic growth without scale effects. Economica, 82(328), 769-789. https://doi.org/10.1111/ecca.12129

Domar, E. D. (1946). Capital expansion, rate of growth, and employment. Econometrica, 14(2), 137-147.

European commission. (2019). Economic Reform Programme of Montenegro (2019-2021), Brussels, 11.4.2019, SWD(2019) 163,pp 1-35, https://data.consilium.europa.eu/doc/document/ST-8547-2019-INIT/en/pdf

European Commission. (2020). european economic forecast-autumn, Institutional Paper 136 | November 2020, 1-224. https://ec.europa.eu/info/business-economy-euro/economic-performance-and-forecasts/ economic-forecasts/autumn-2020-economic-forecast_en

Gu, X., Huang, B., Sun Tam, P., \& Zhang, Y. (2015). Inequality and saving: Further evidence from integrated economies. Review of Development Economics, 19(1), 15-30.

Harrod, R. F. (1939). An essay in dynamic theory. Economic Journal, 49, 14-33.

Jiménez-Rodriguez, R., Morales-Zumaquero, A., \& Égert, B. (2013). Business cycle synchronization between euro area and central and eastern European countries. Re-View of Development Economics, 17(2), $379-395$.

Kaldor, N. (1963). Capital accumulation and economic growth. Seminar on the programming of economic development, King's College, Cambridge. http://www.fep.up.pt/docentes/joao/material/macro2/Kaldor_ 1961.pdf

Keynes, J. M. (1936). The general theory of employment, interest and money. Macmillan.

Parsons, T., \& Smelser, N. J. (2005). Parsons's economic sociology and its extension to the global economy. Journal of Classical Sociology, 5, 245-266.

Sala-i-Martin, X. (1996). The classical approach to convergence analysis. Economic Journal, 106(437), $1019-1036$.

Scharpf, F. W. (2010). The asymmetry of European integration, or why the EU cannot Be a 'social market economy. Socio-Economic Review, 8(2), 211-250.

Stanciu, S., Zlati, M. L., Antohi, V. M., \& Bichescu, C. I. (2019). The Development Analysis Of The Romanian Traditional Product Market Based On The Performance Model For Sustainable Economic Development. Sustainability, 11, 11-23. https://doi.org/10.3390/su11041123

Stone, J. (2018). Serbia and Montenegro could join EU by 2025. The Independent, $26^{\text {th }}$ of February, Retrieved from: http://www.independent.co.uk/news/world/europe/eu-enlargement-serbia-montenegro-macedoniaalbania-kosovo-brexit-juncker-2025-a8197201.html

Wiener, A., Börzel, T.A. \& Risse, T. (2018). European Integration Theory. Oxford University Press, Third Edition.

Publisher's Note Springer Nature remains neutral with regard to jurisdictional claims in published maps and institutional affiliations. 